\title{
A Formal Total Synthesis of the Salicylihalamides
}

\author{
Christian Herb and Martin E. Maier*
}

Institut für Organische Chemie, Universität Tübingen, Auf der Morgenstelle 18, D-72076 Tübingen, Germany

martin.e.maier@uni-tuebingen.de

\section{Supporting Information}

Table of contents

${ }^{1} \mathrm{H}$ nmr spectrum of benzoate 3

${ }^{13} \mathrm{C}$ nmr spectrum of benzoate 3

${ }^{1} \mathrm{H}$ nmr spectrum of aldehyde 4

${ }^{13} \mathrm{C} \mathrm{nmr}$ spectrum of aldehyde 4

${ }^{1} \mathrm{H}$ nmr spectrum of vinyl iodide 5

${ }^{13} \mathrm{C}$ nmr spectrum of vinyl iodide $\mathbf{5}$

${ }^{1} \mathrm{H}$ nmr spectrum of aldehyde 7

${ }^{13} \mathrm{C}$ nmr spectrum of aldehyde 7

${ }^{1} \mathrm{H}$ nmr spectrum of keto ester 8

${ }^{13} \mathrm{C}$ nmr spectrum of keto ester 8

${ }^{1} \mathrm{H}$ nmr spectrum of hydroxy ester 9

${ }^{13} \mathrm{C}$ nmr spectrum of hydroxy ester 9

${ }^{1} \mathrm{H}$ nmr spectrum of ester $\mathbf{1 0}$

${ }^{13} \mathrm{C}$ nmr spectrum of ester 10

${ }^{1} \mathrm{H}$ nmr spectrum of aldehyde $\mathbf{1 1}$

${ }^{13} \mathrm{C} \mathrm{nmr}$ spectrum of aldehyde $\mathbf{1 1}$

${ }^{1} \mathrm{H}$ nmr spectrum of aldol product $\mathbf{1 3}$

${ }^{13} \mathrm{C} \mathrm{nmr}$ spectrum of aldol product $\mathbf{1 3}$

${ }^{1} \mathrm{H}$ nmr spectrum of MOM ether $\mathbf{1 4}$ page

S3

S4

S5

S6

S7

S8

S9

S10

S11

S12

S13

S14

S15

S16

S17

S18

S19

S20

S21 
${ }^{13} \mathrm{C}$ nmr spectrum of MOM ether $14 \quad \mathrm{~S} 22$

$\begin{array}{ll}{ }^{1} \mathrm{H} \text { nmr spectrum of alcohol } 15 & \text { S23 }\end{array}$

$\begin{array}{ll}{ }^{13} \mathrm{C} \text { nmr spectrum of alcohol } \mathbf{1 5} & \text { S24 }\end{array}$

$\begin{array}{ll}{ }^{1} \mathrm{H} \text { nmr spectrum of tosylate } \mathbf{1 6} & \mathrm{S} 25\end{array}$

${ }^{13} \mathrm{C}$ nmr spectrum of tosylate $\mathbf{1 6} \quad \mathrm{S} 26$

$\begin{array}{ll}{ }^{1} \mathrm{H} \text { nmr spectrum of alkene } \mathbf{1 7} & \text { S27 }\end{array}$

$\begin{array}{ll}{ }^{13} \mathrm{C} \mathrm{nmr} \text { spectrum of alkene } \mathbf{1 7} & \text { S28 }\end{array}$

$\begin{array}{ll}{ }^{1} \mathrm{H} \text { nmr spectrum of coupling product } \mathbf{1 8} & \text { S29 }\end{array}$

$\begin{array}{ll}{ }^{13} \mathrm{C} \mathrm{nmr} \text { spectrum of coupling product } \mathbf{1 8} & \text { S30 }\end{array}$

$\begin{array}{ll}{ }^{1} \mathrm{H} \text { nmr spectrum of iodide } 19 & \text { S31 }\end{array}$

$\begin{array}{ll}{ }^{13} \mathrm{C} \text { nmr spectrum of iodide } 19 & \text { S32 }\end{array}$

$\begin{array}{ll}{ }^{1} \mathrm{H} \text { nmr spectrum of hydroxy ester } 20 & \text { S33 }\end{array}$

$\begin{array}{ll}{ }^{13} \mathrm{C} \text { nmr spectrum of hydroxy ester } 20 & \text { S34 }\end{array}$

$\begin{array}{ll}{ }^{1} \mathrm{H} \text { nmr spectrum of hydroxy acid } 21 & \text { S35 }\end{array}$

${ }^{13} \mathrm{C}$ nmr spectrum of hydroxy acid $21 \quad$ S36

$\begin{array}{ll}{ }^{1} \mathrm{H} \text { nmr spectrum of macrolactone } 23 & \text { S37 }\end{array}$

${ }^{13} \mathrm{C}$ nmr spectrum of macrolactone $\mathbf{2 3} \quad$ S38 


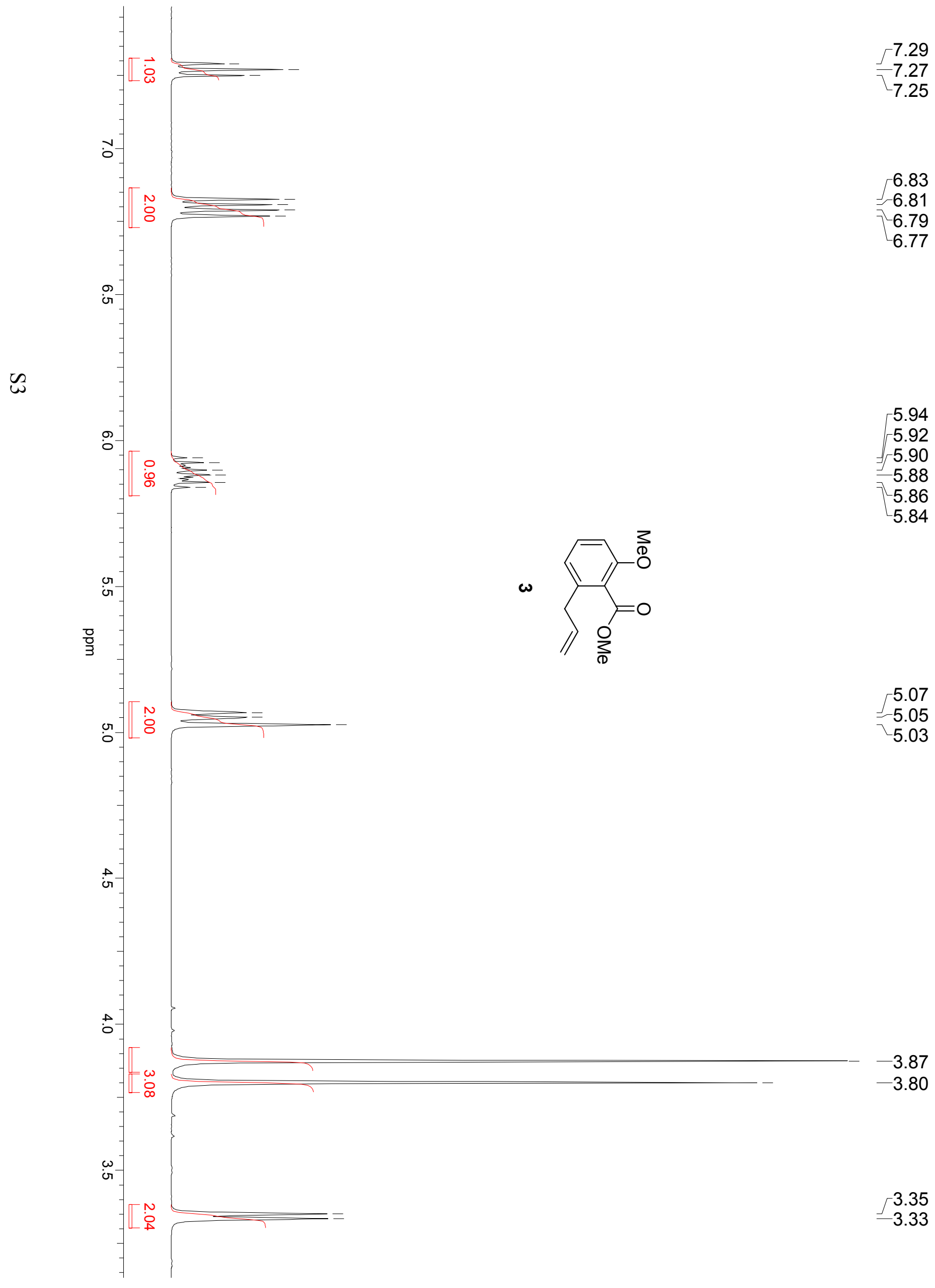




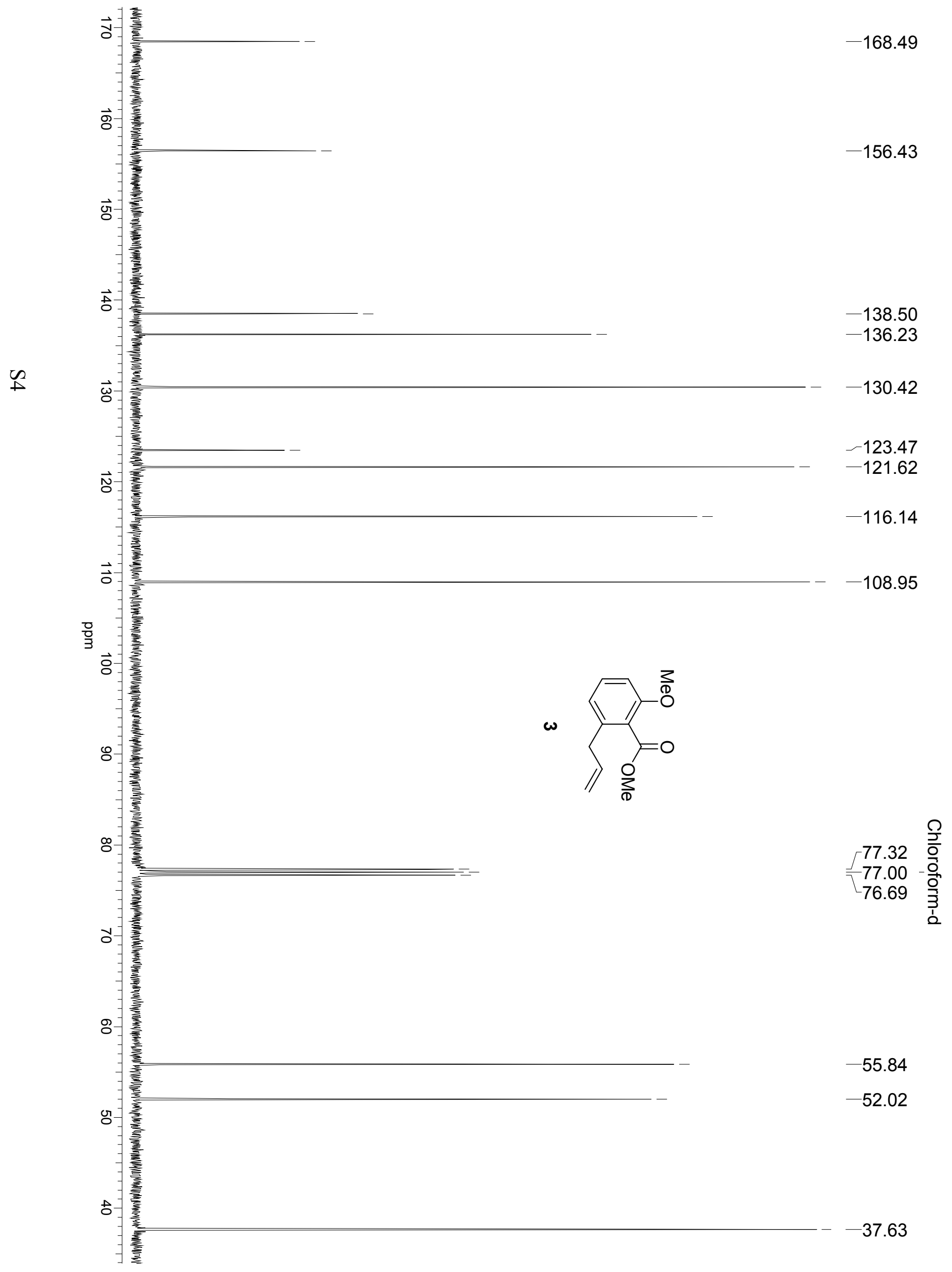




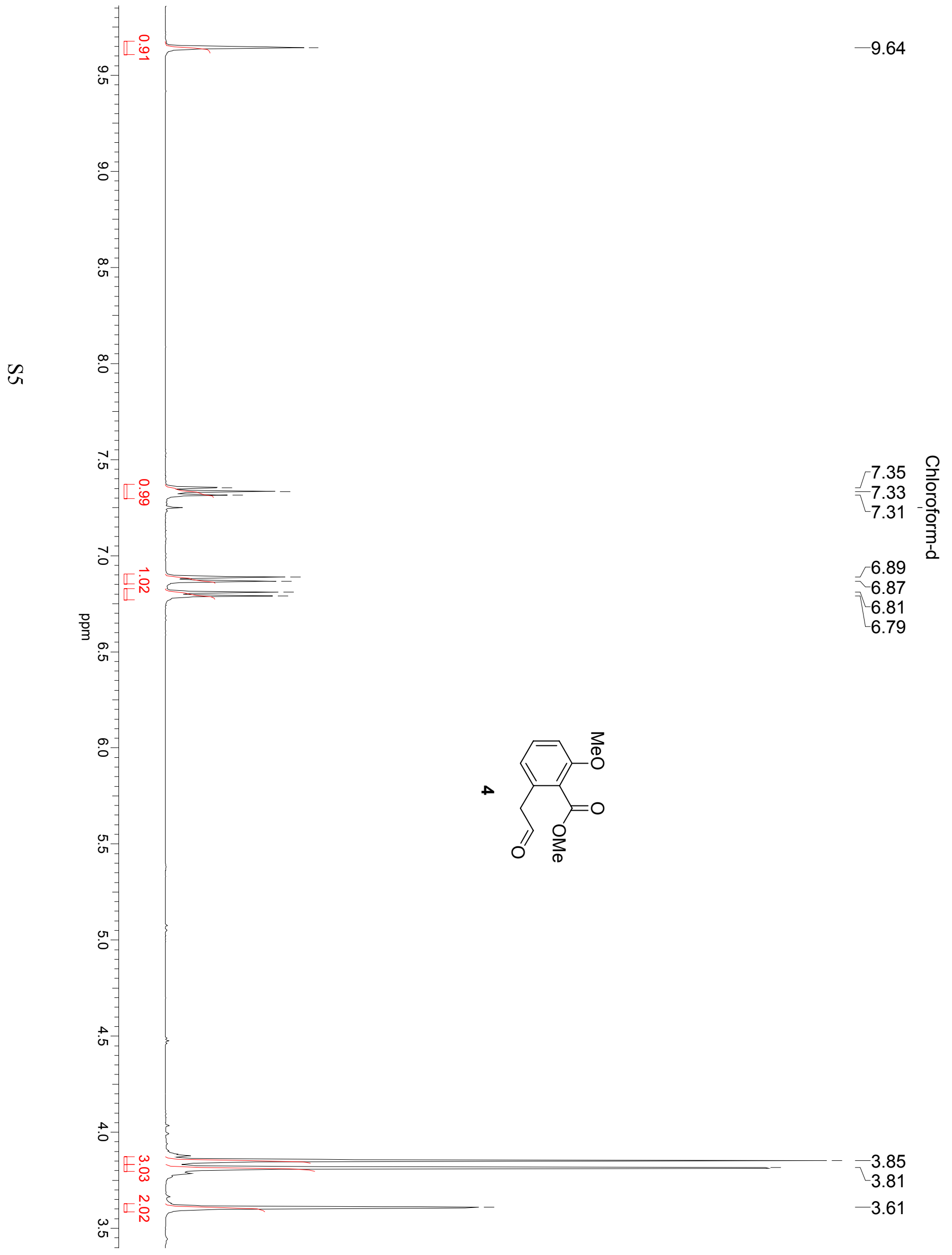




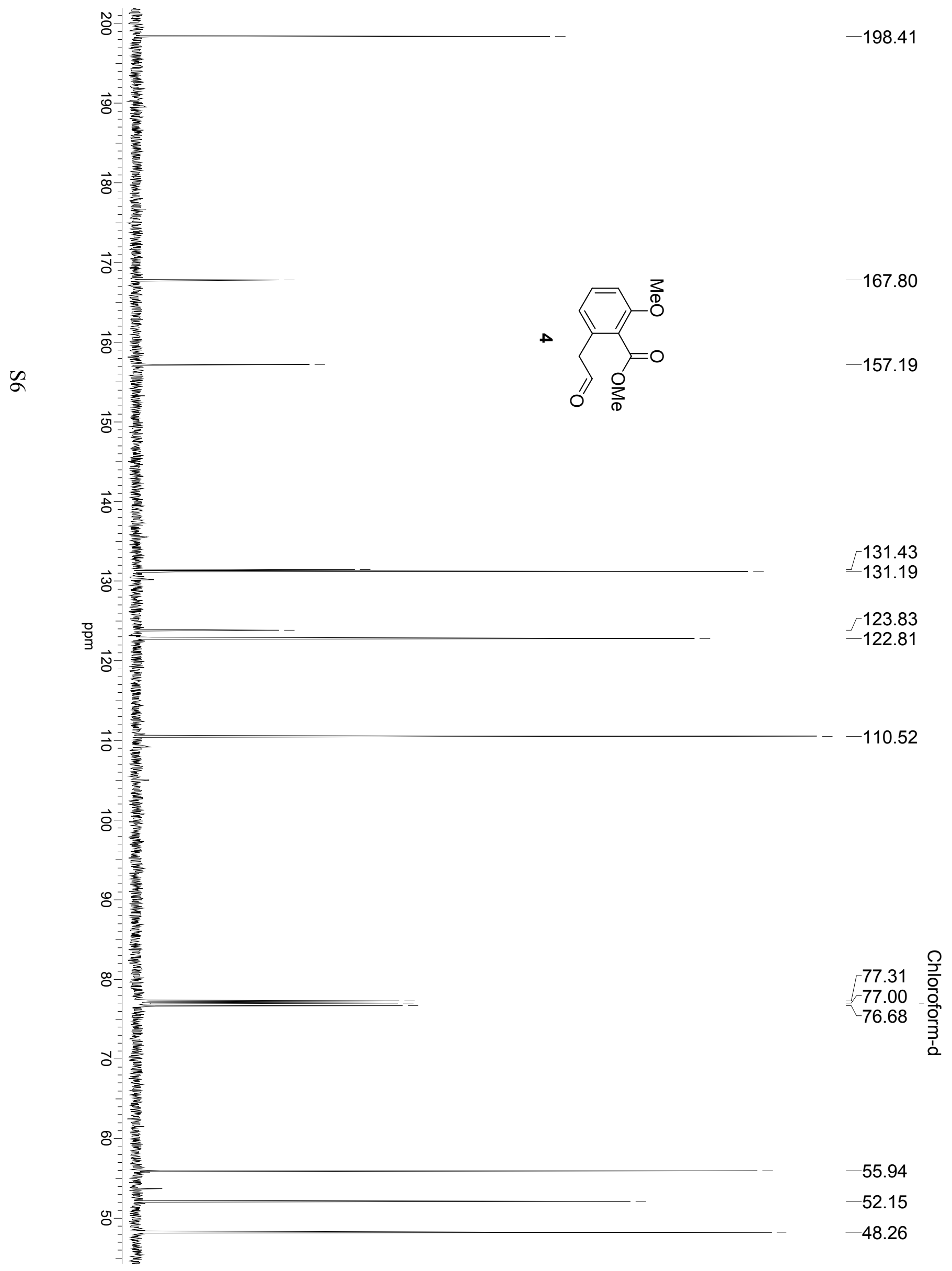




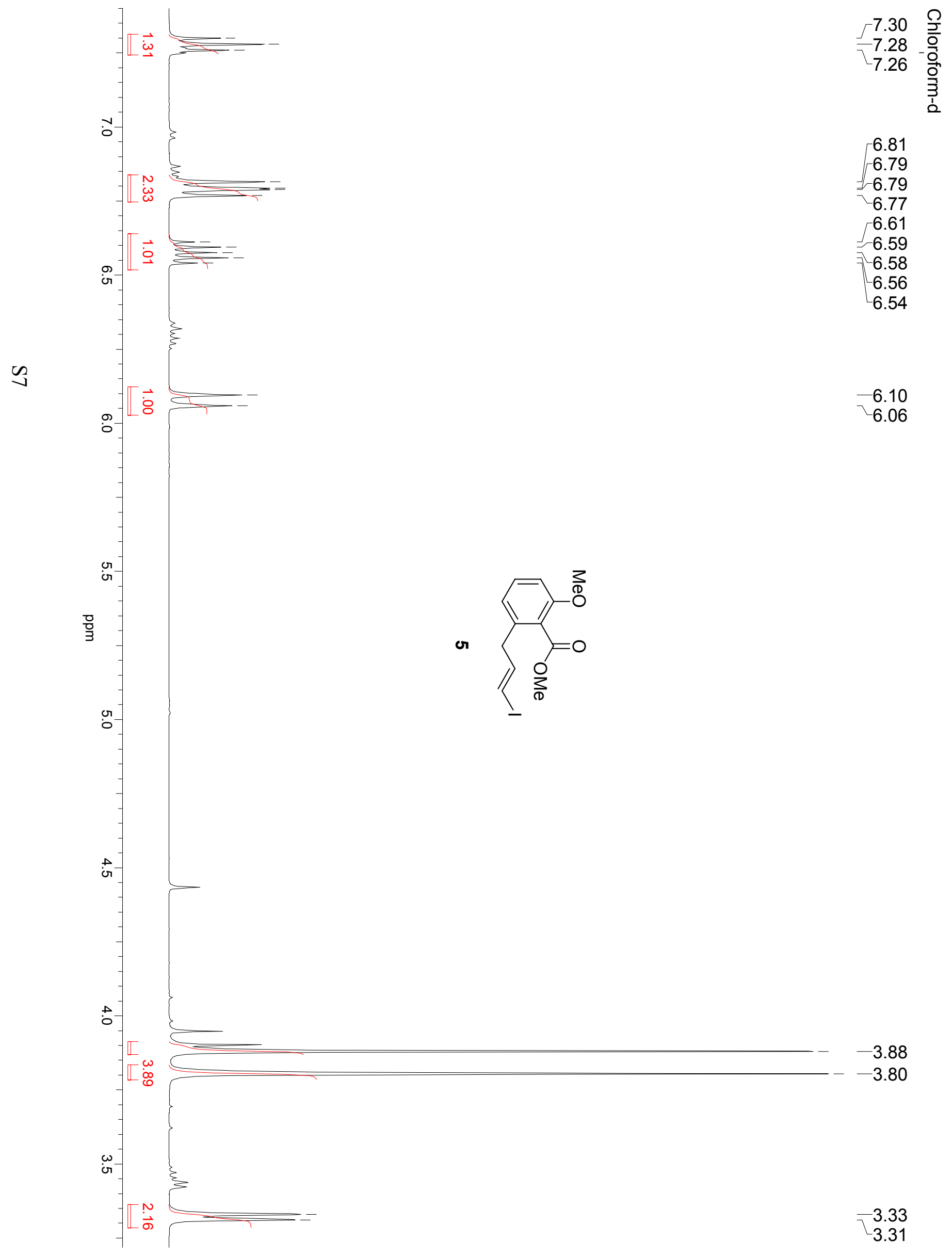




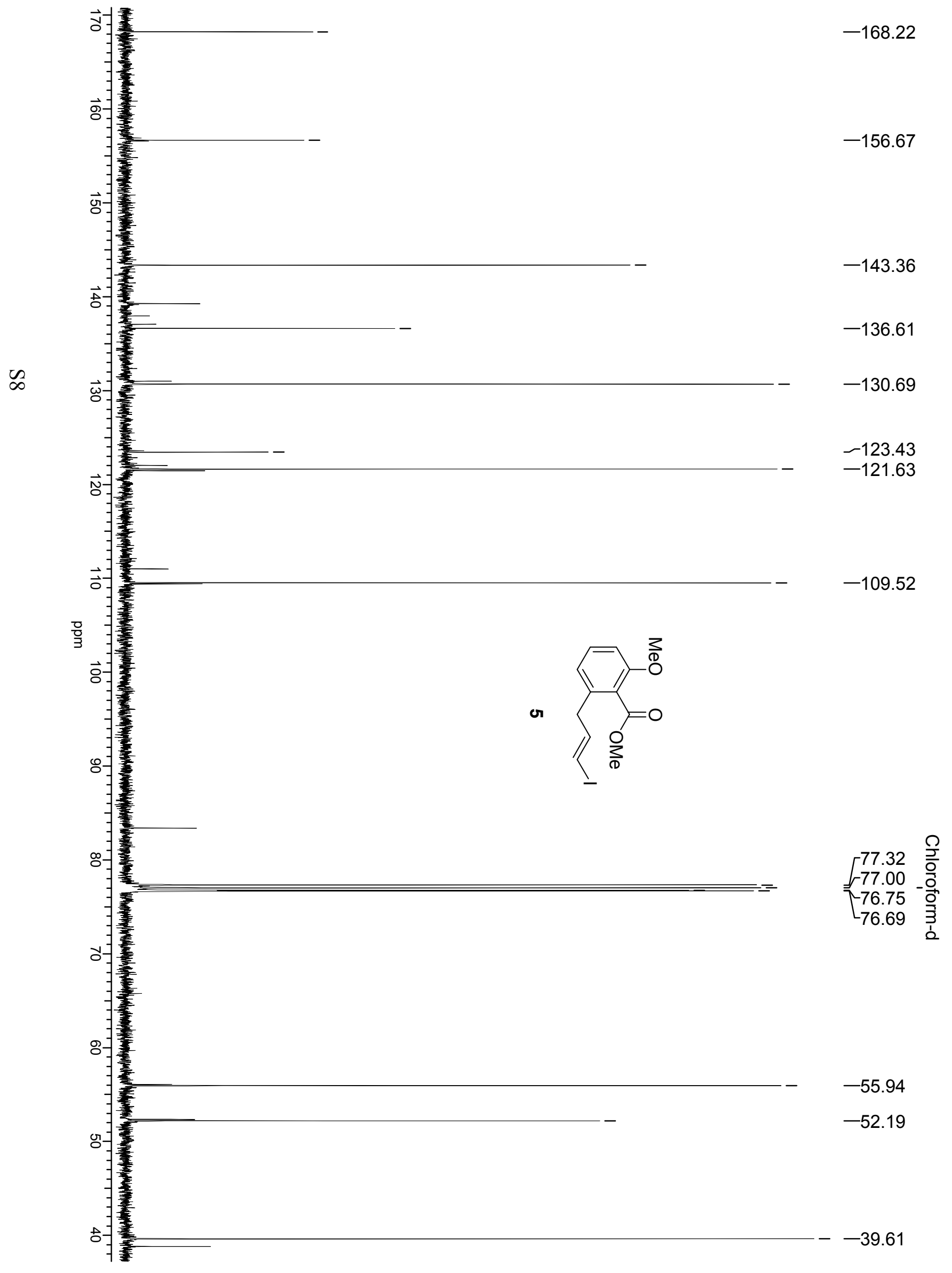




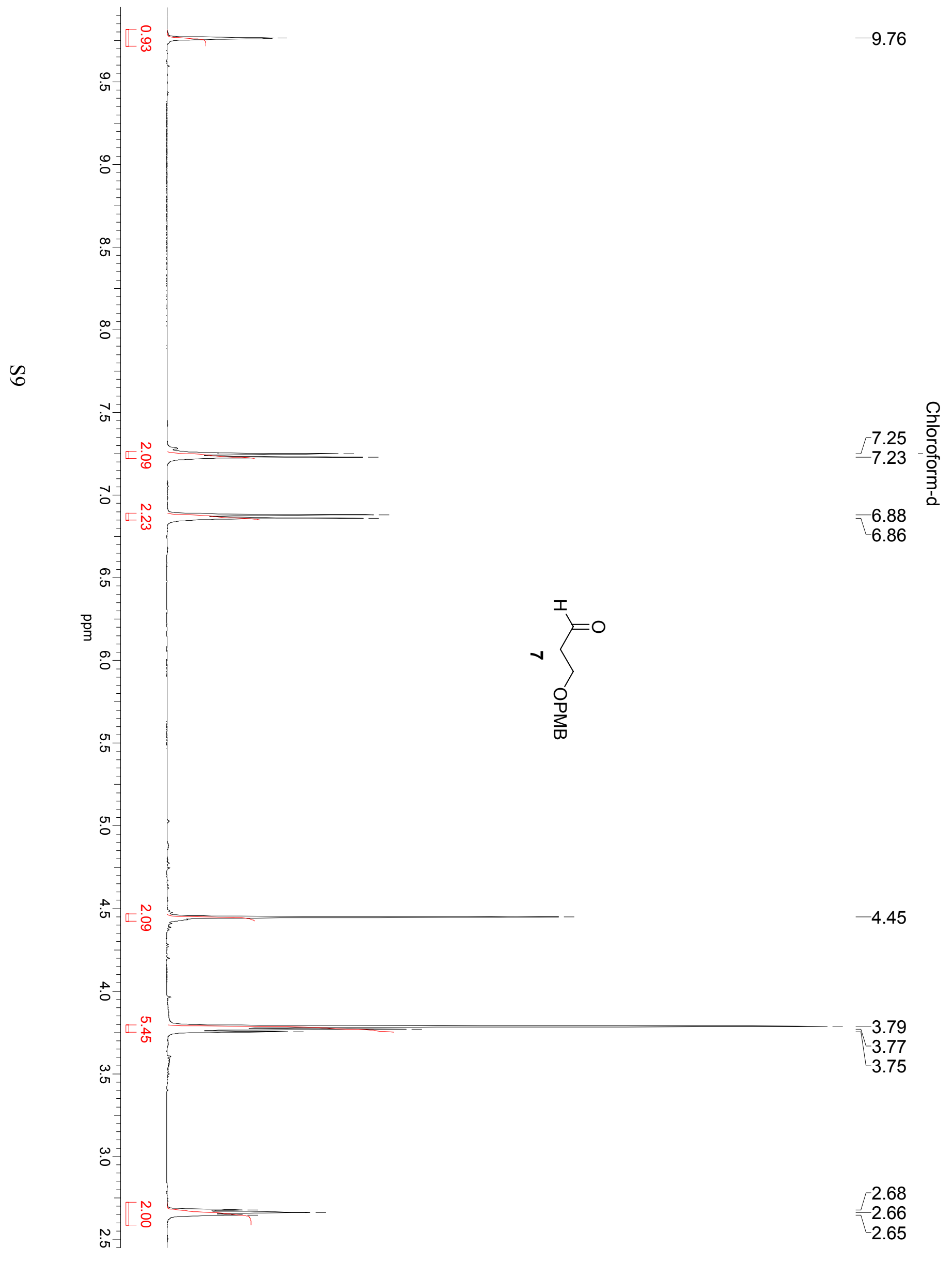




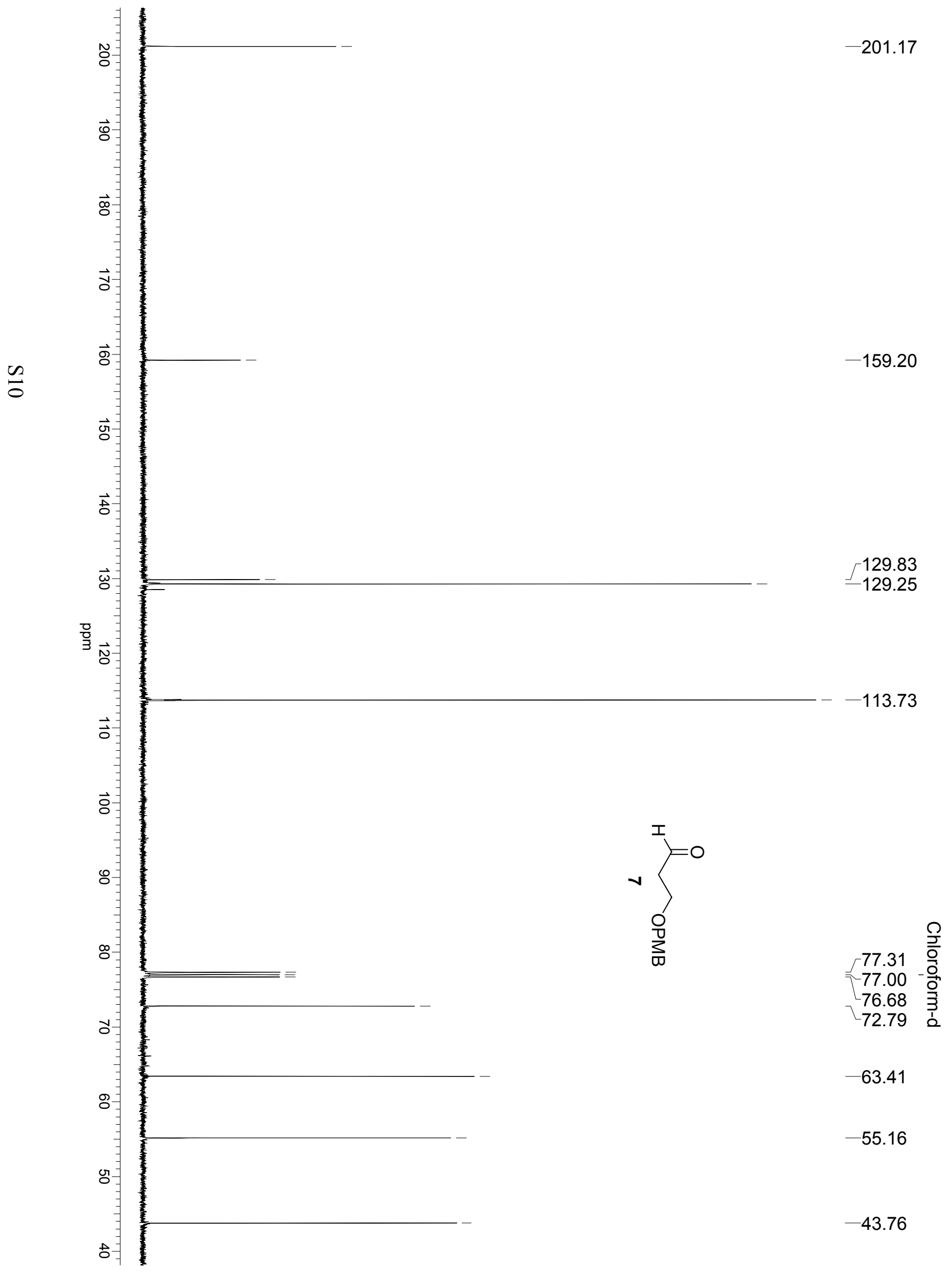




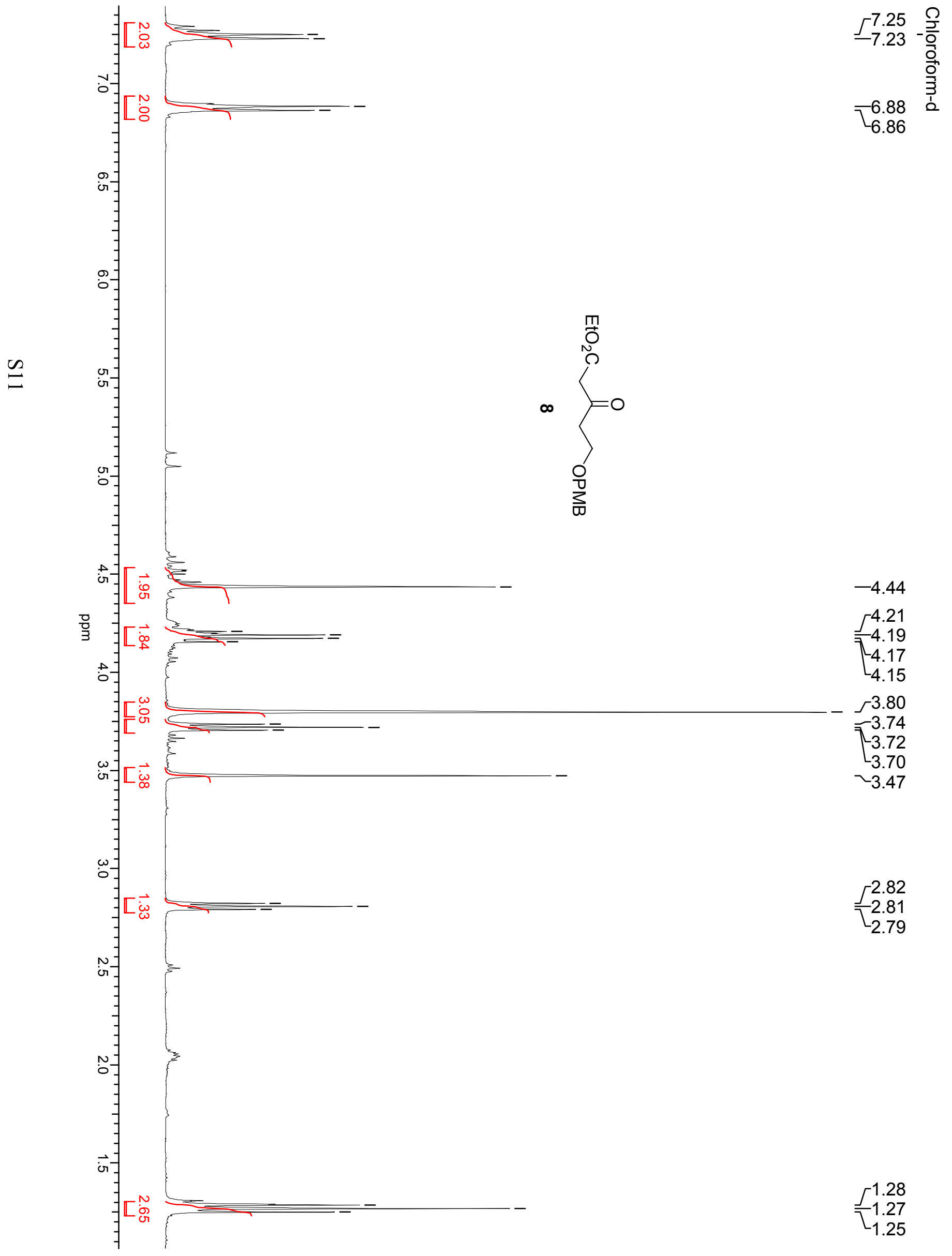




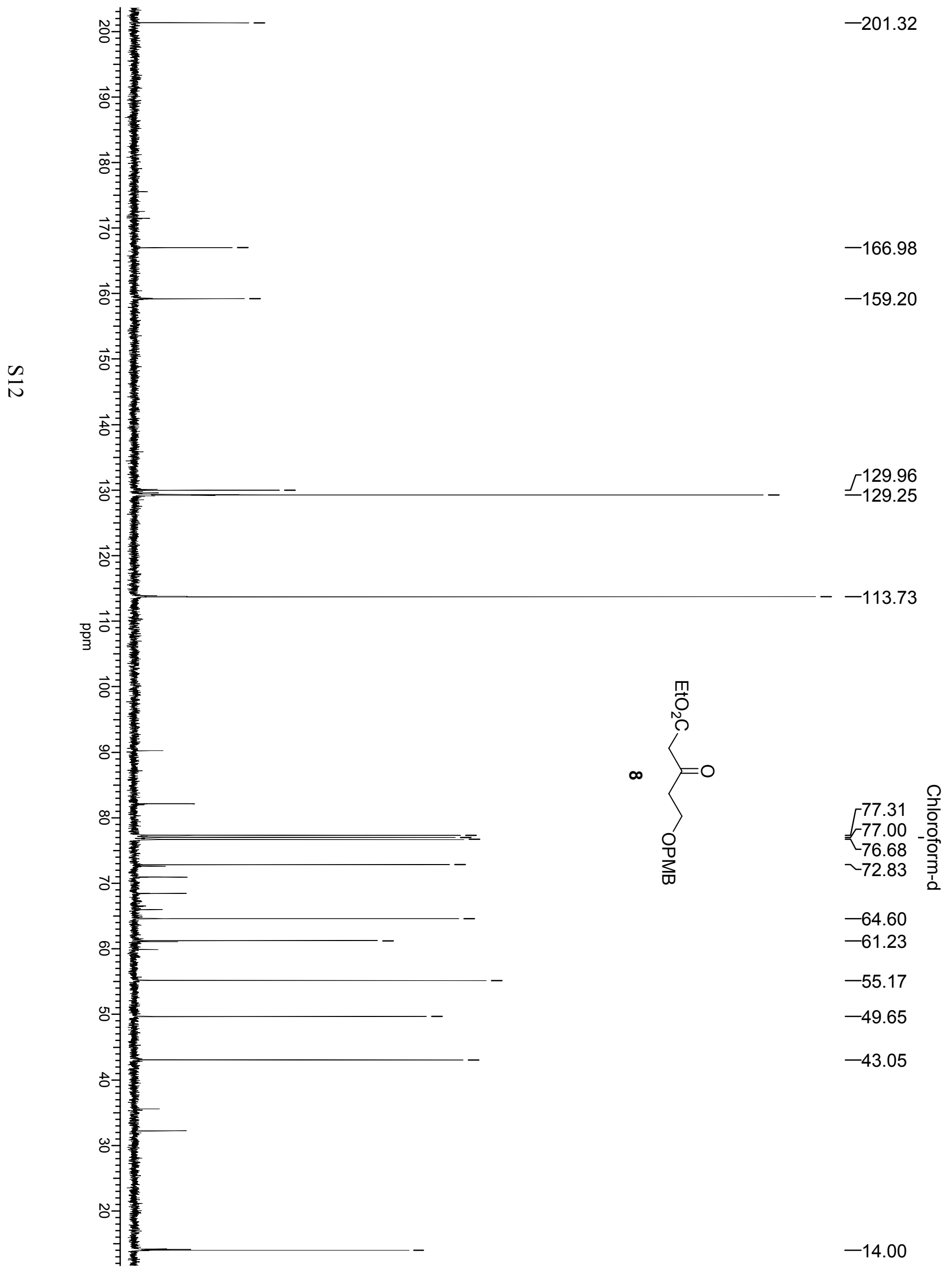




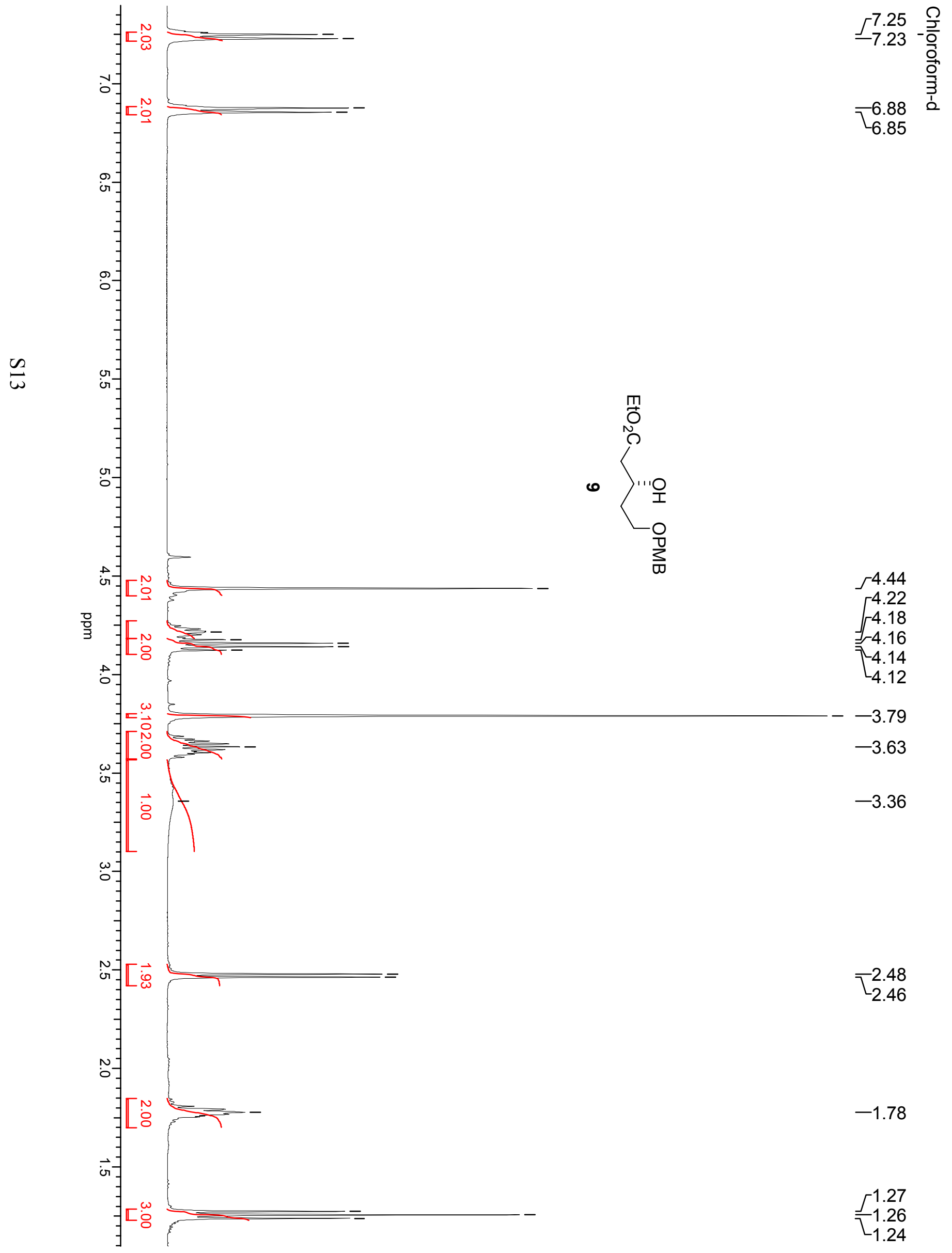




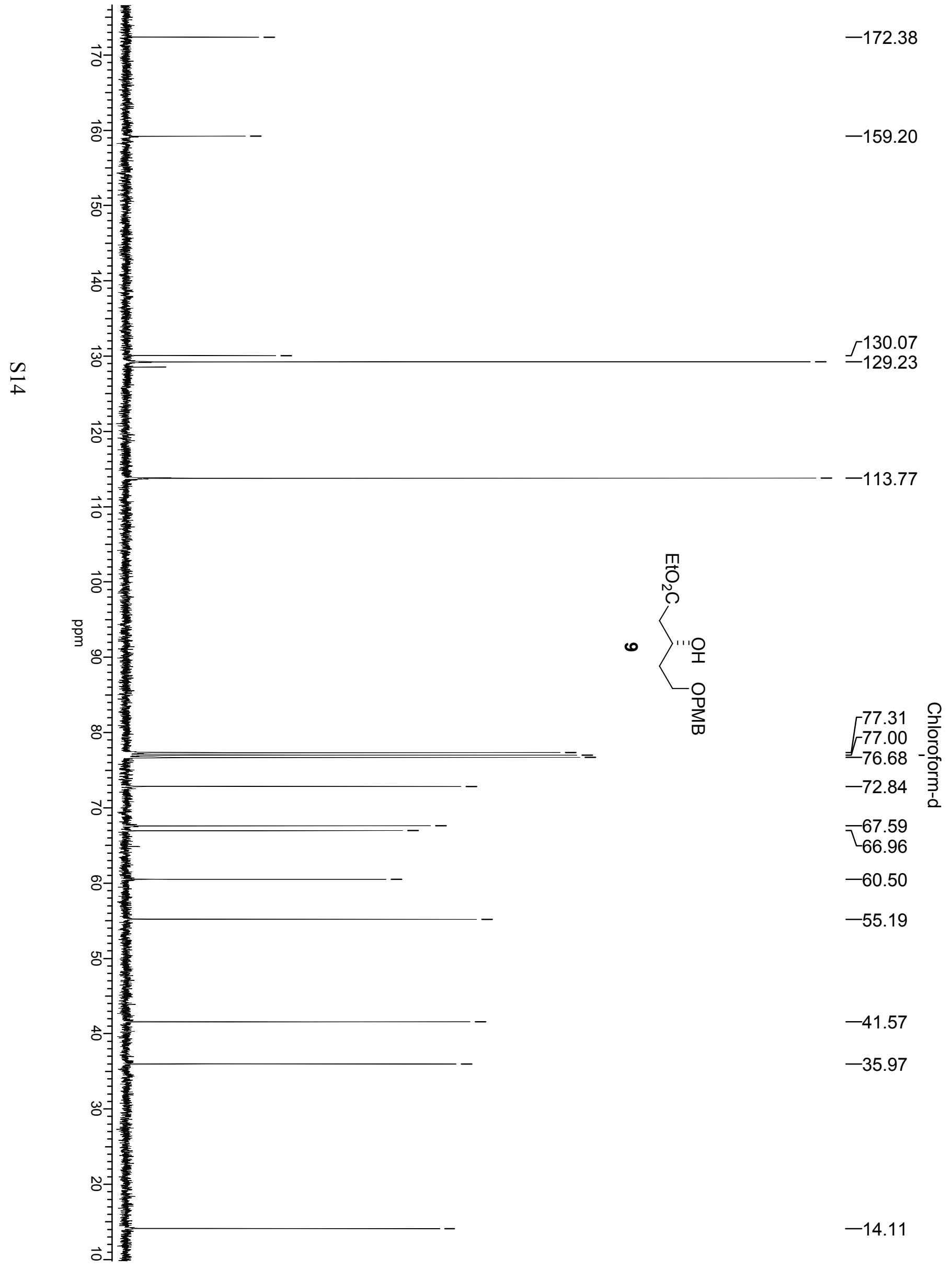




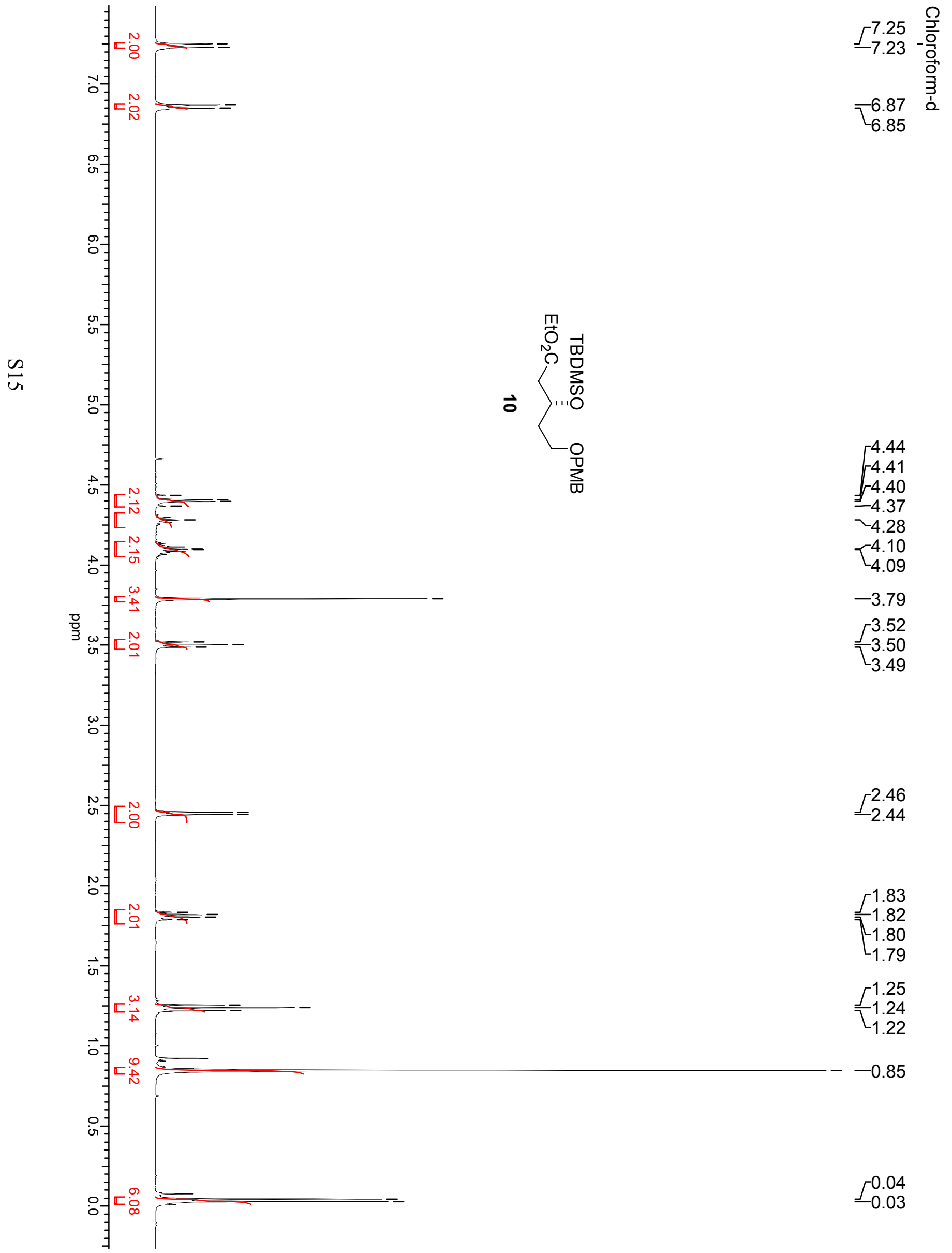




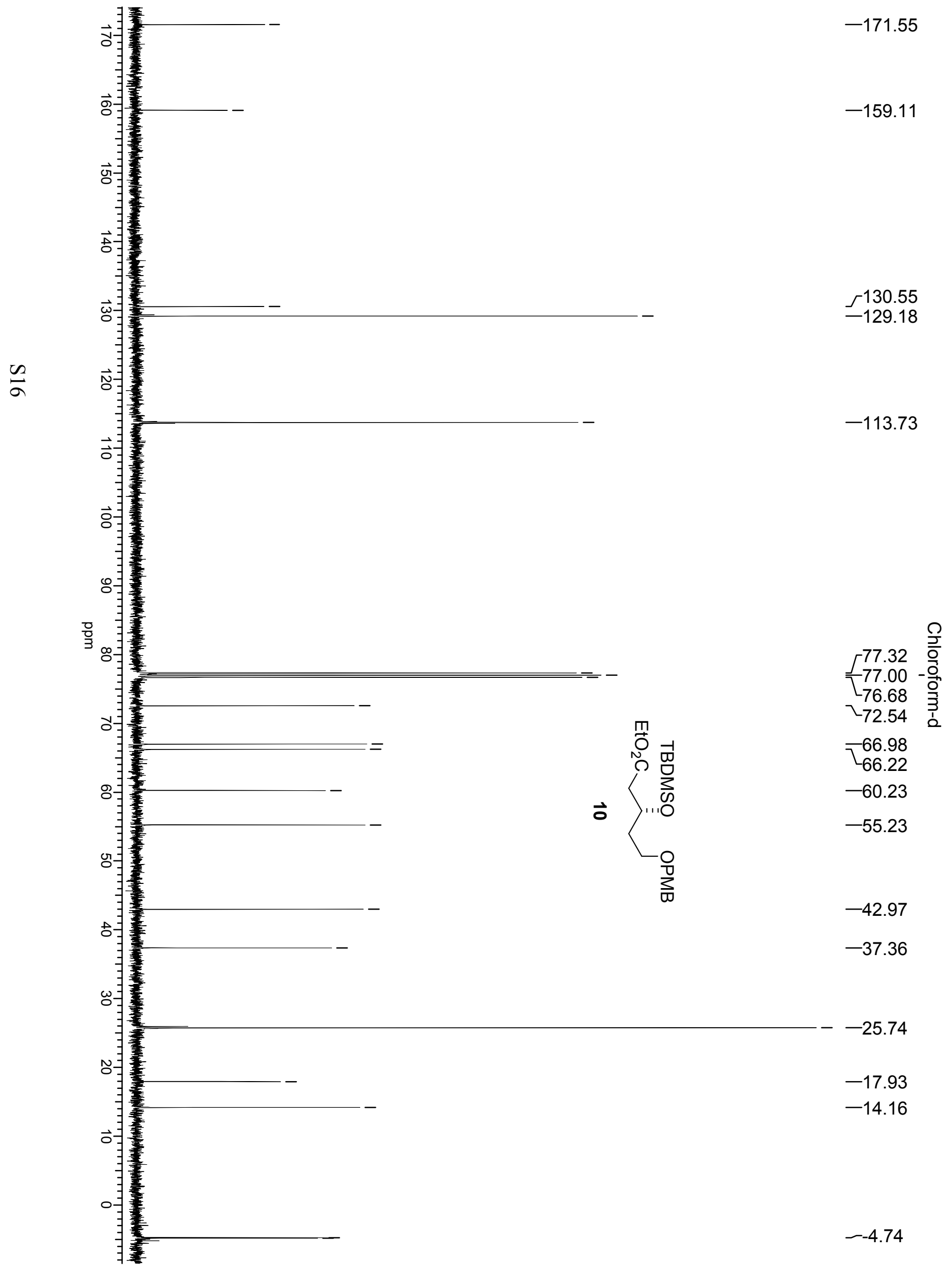




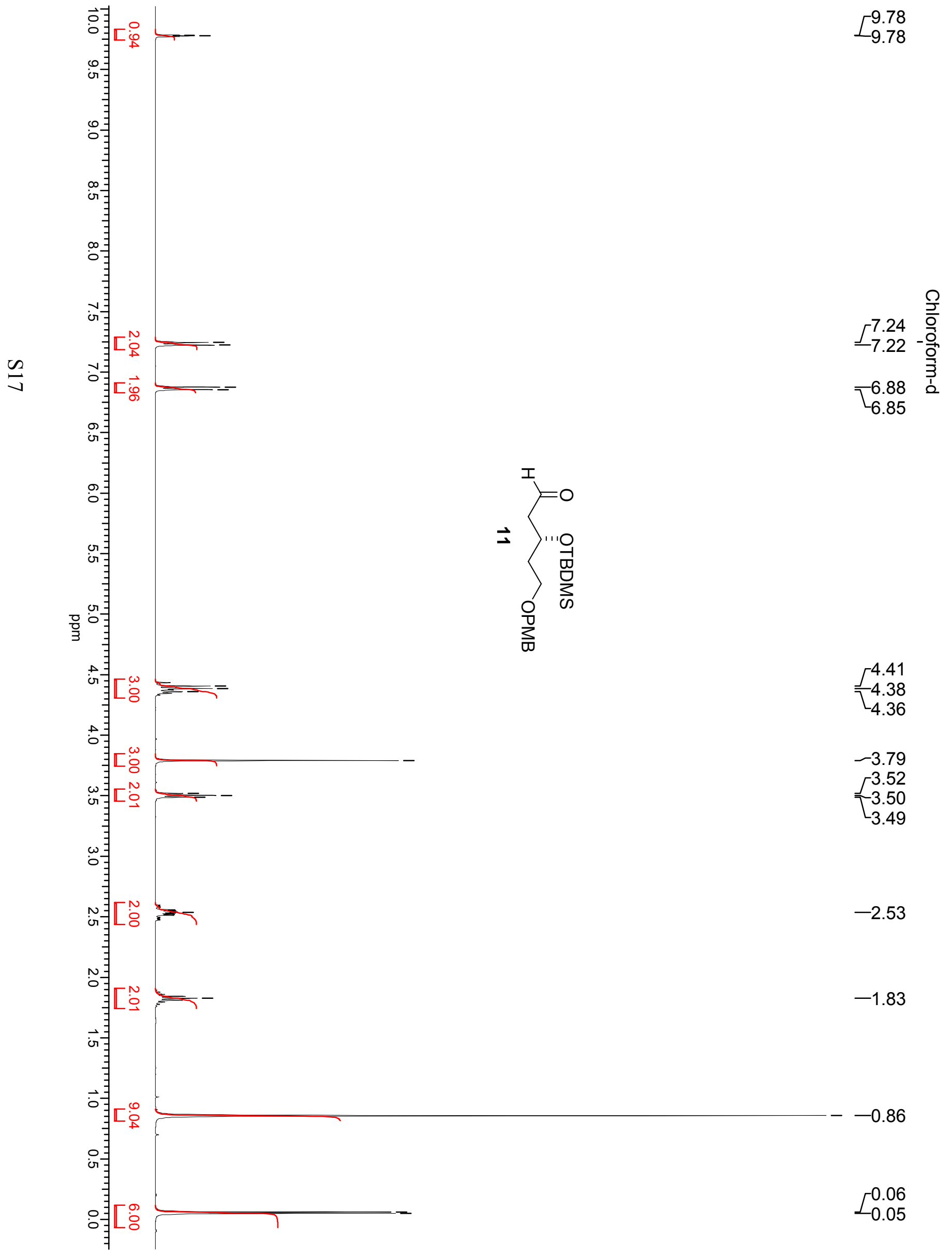




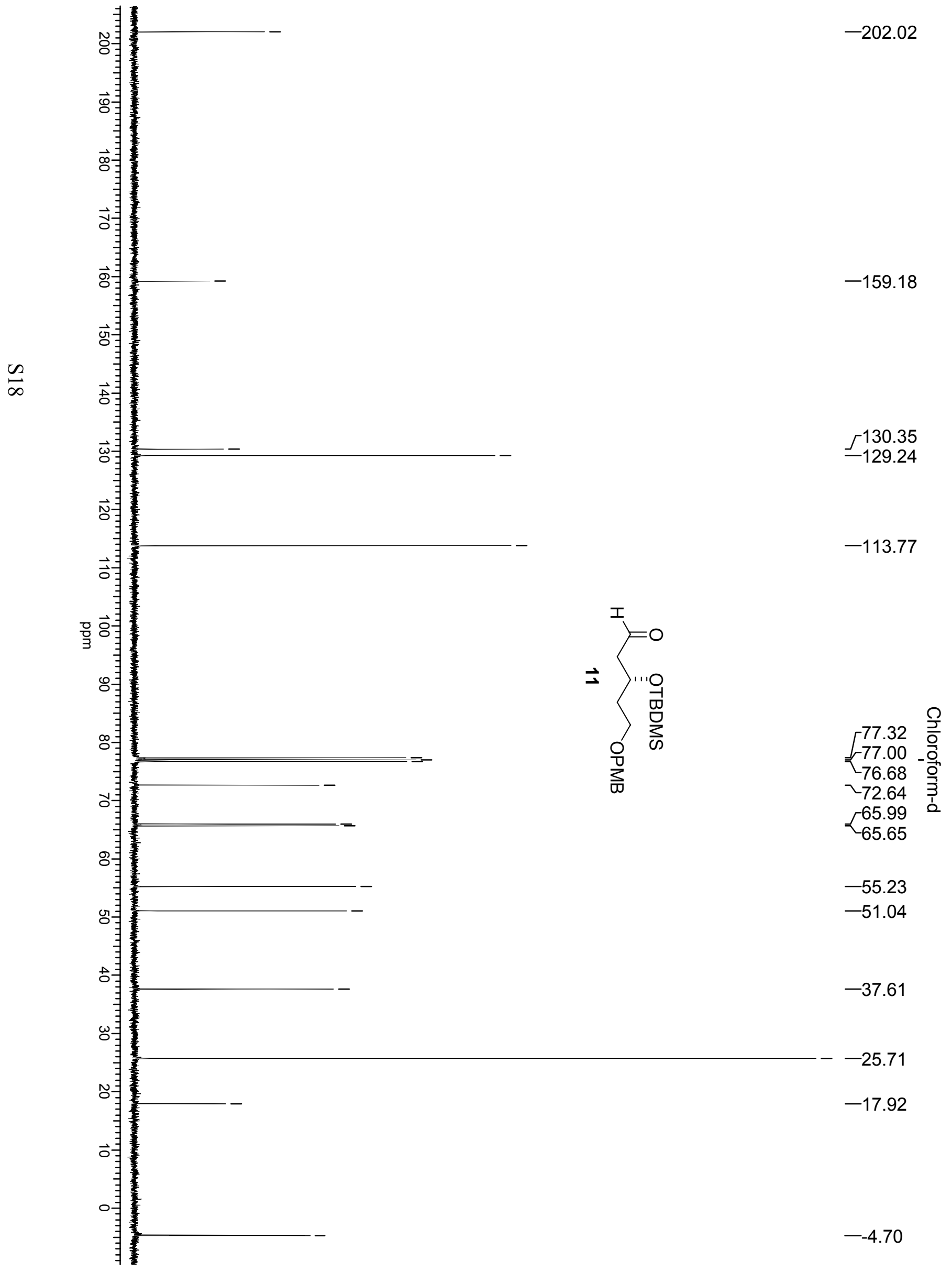




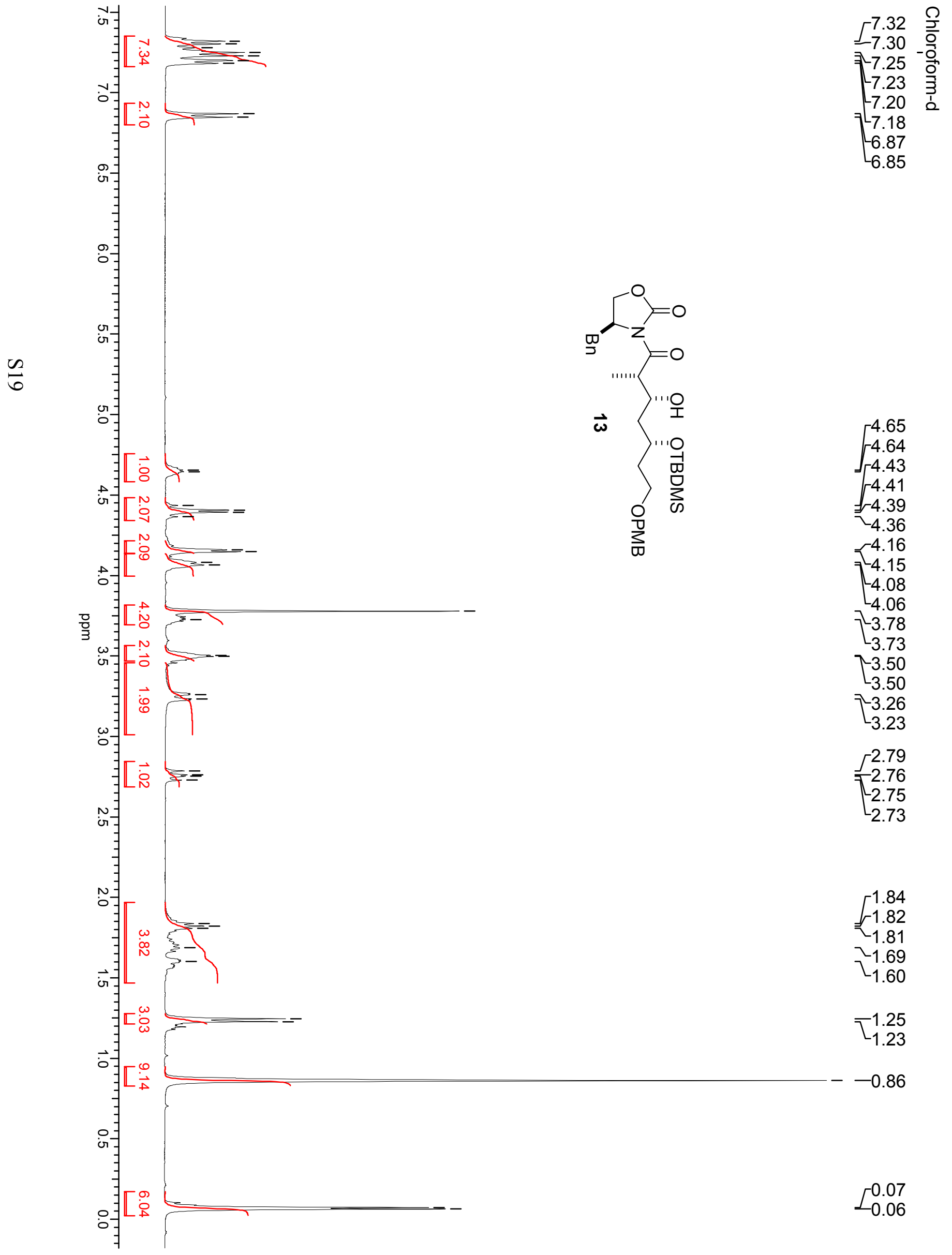




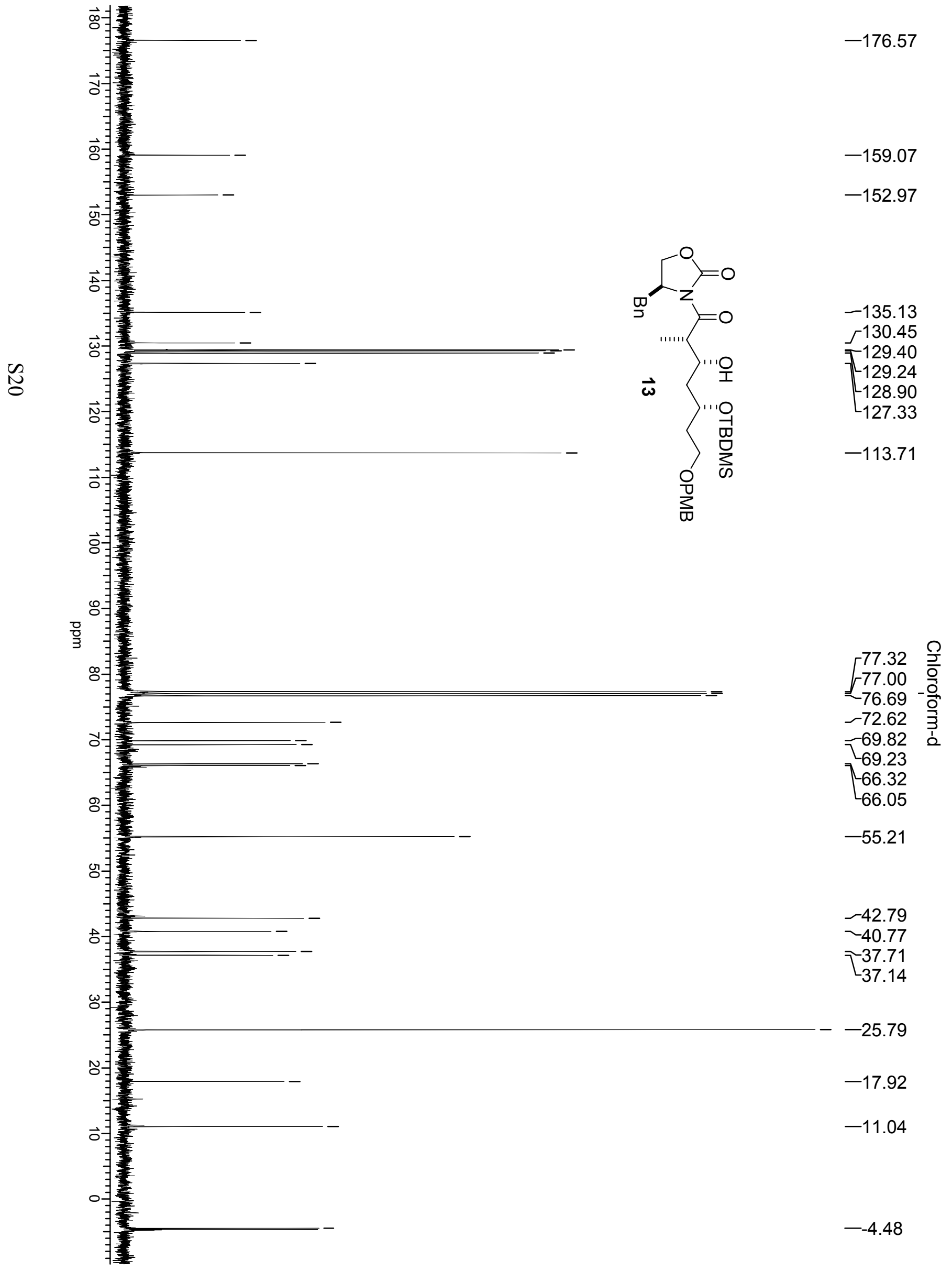




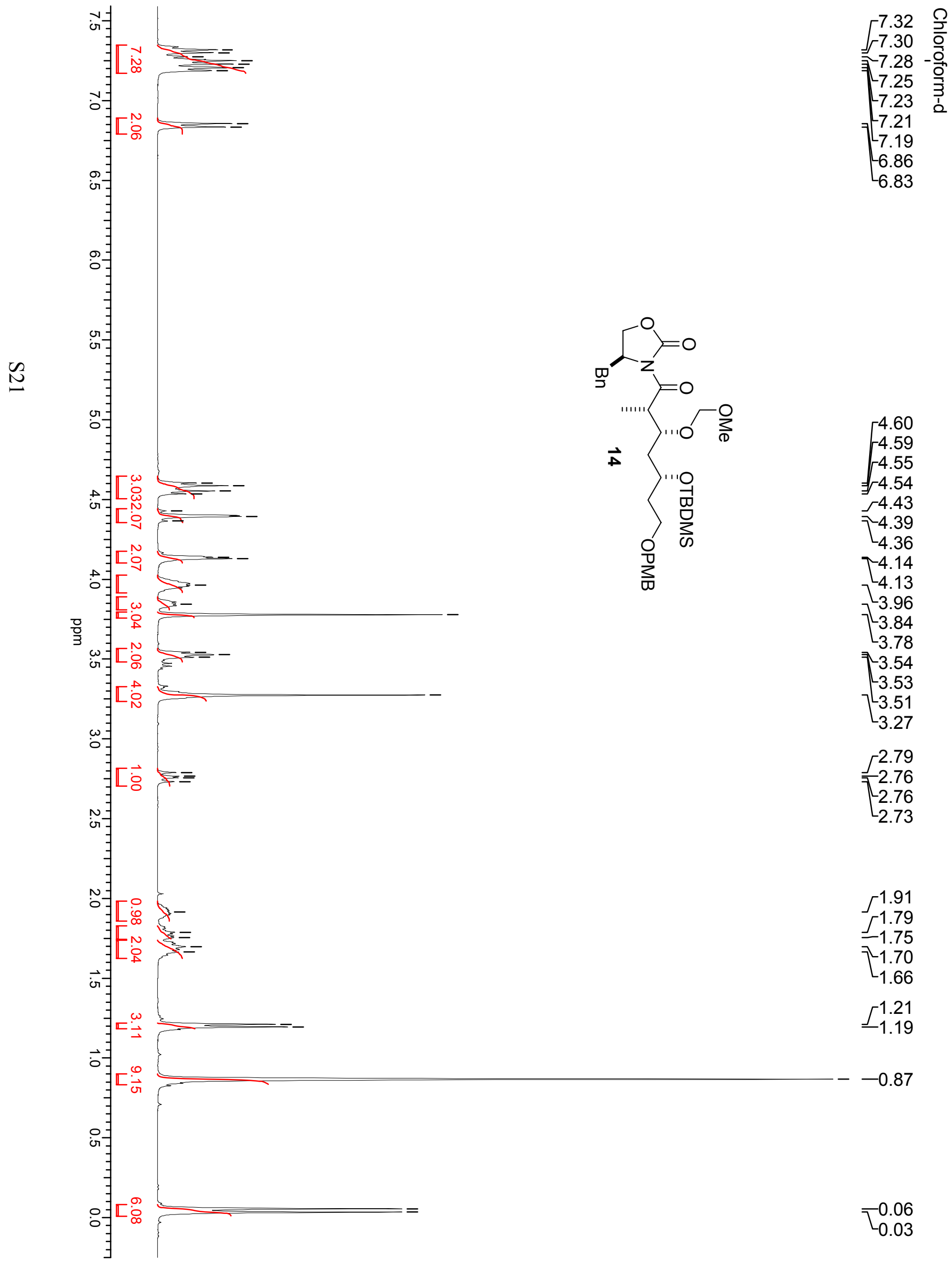




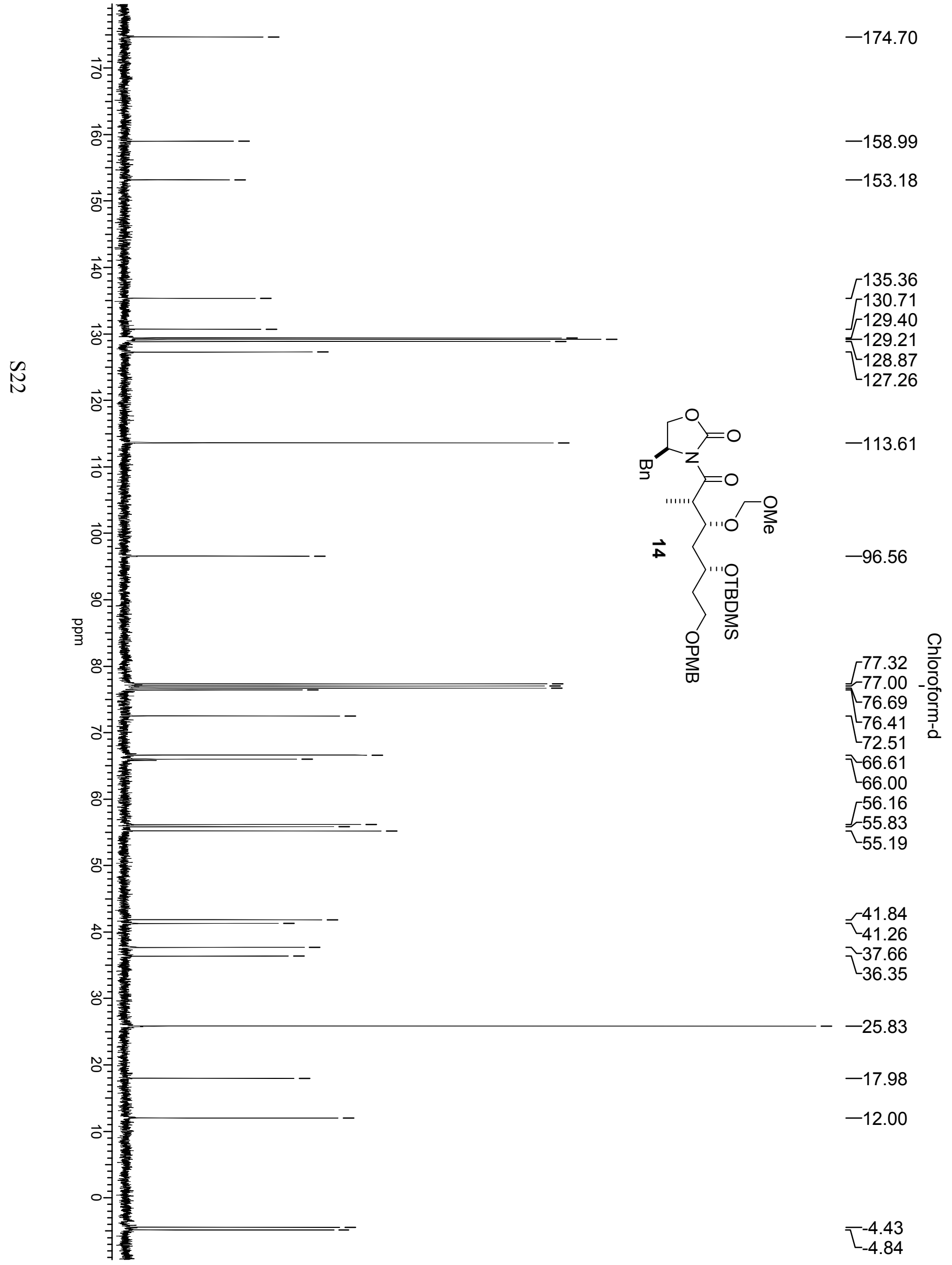




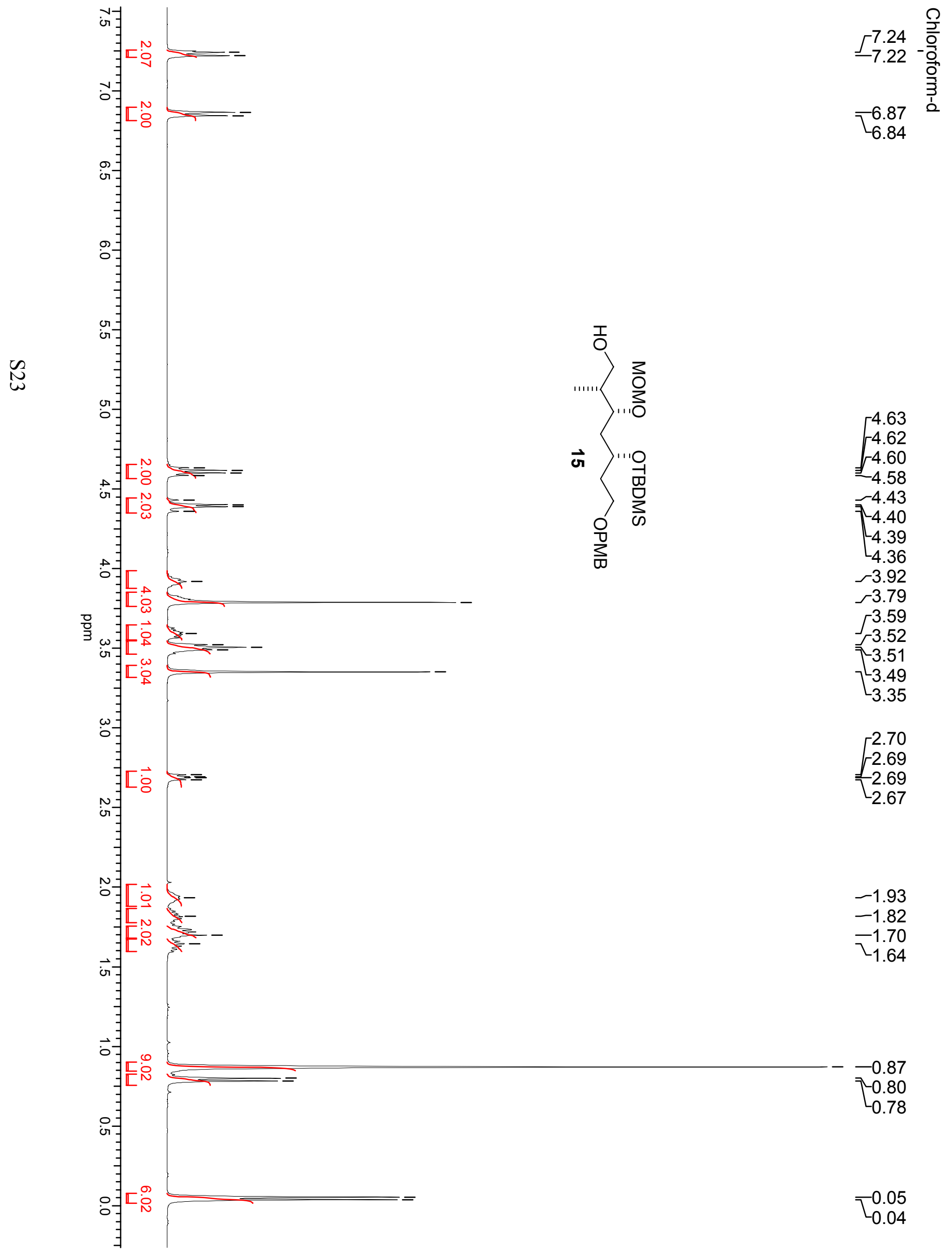




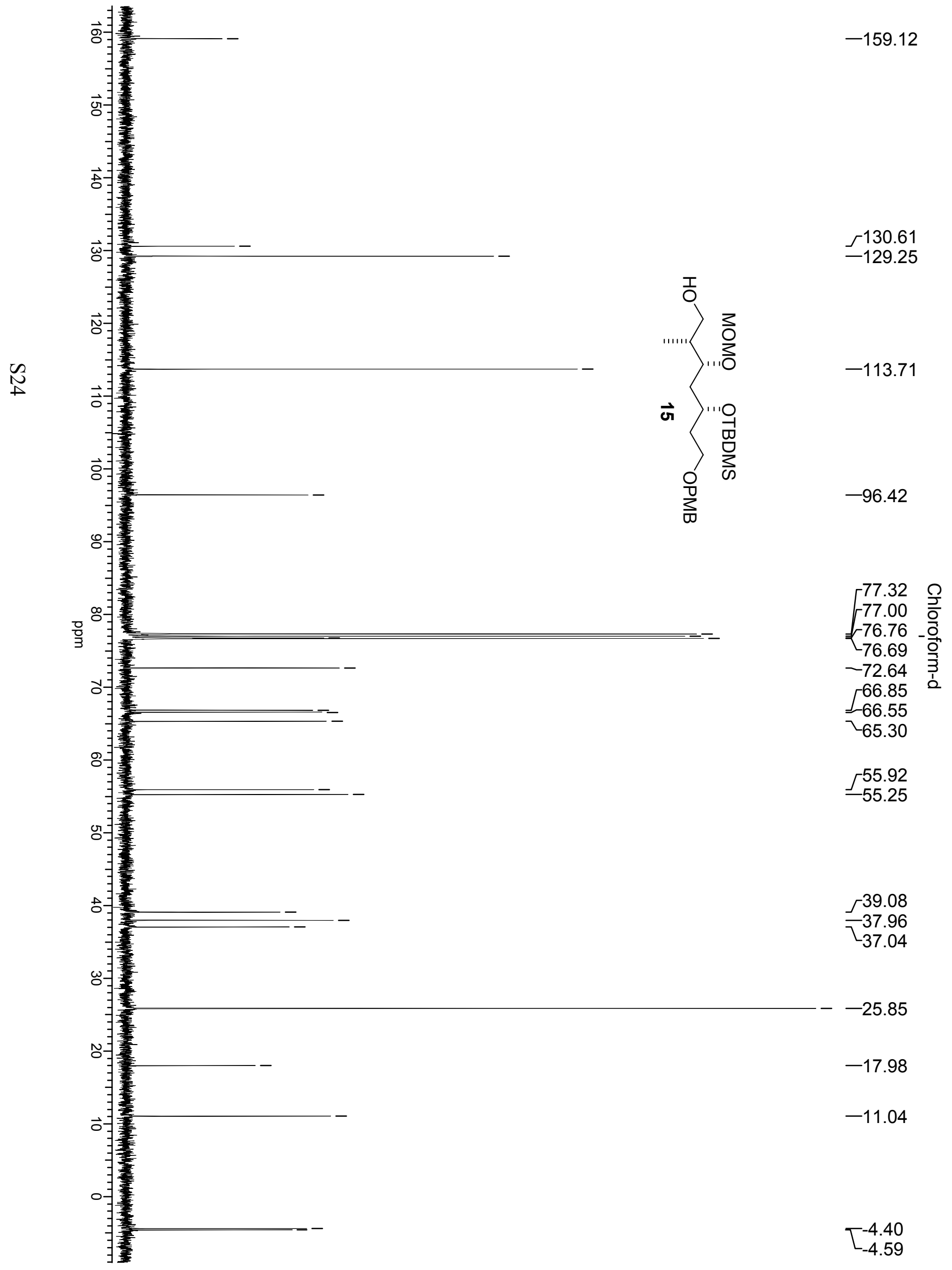




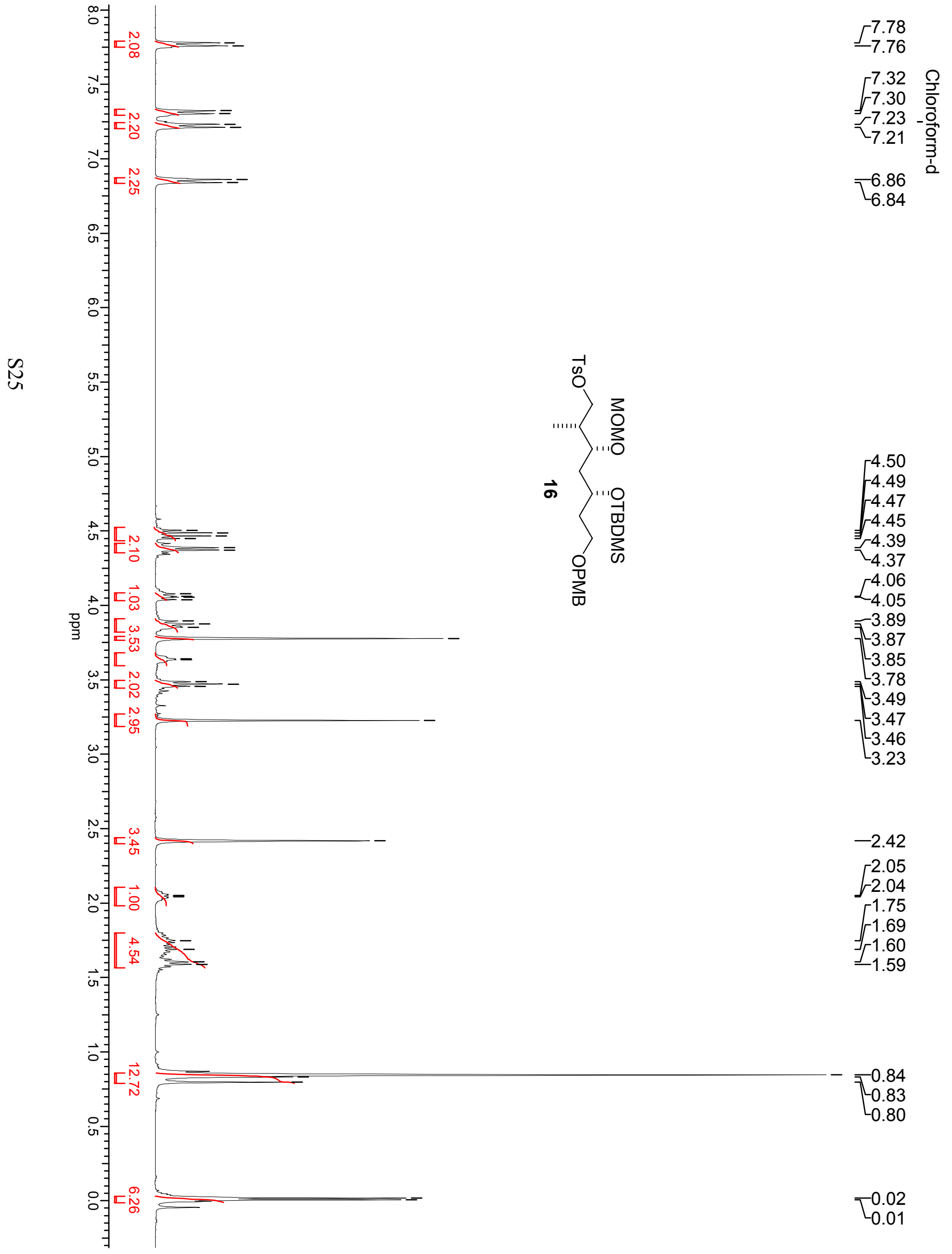




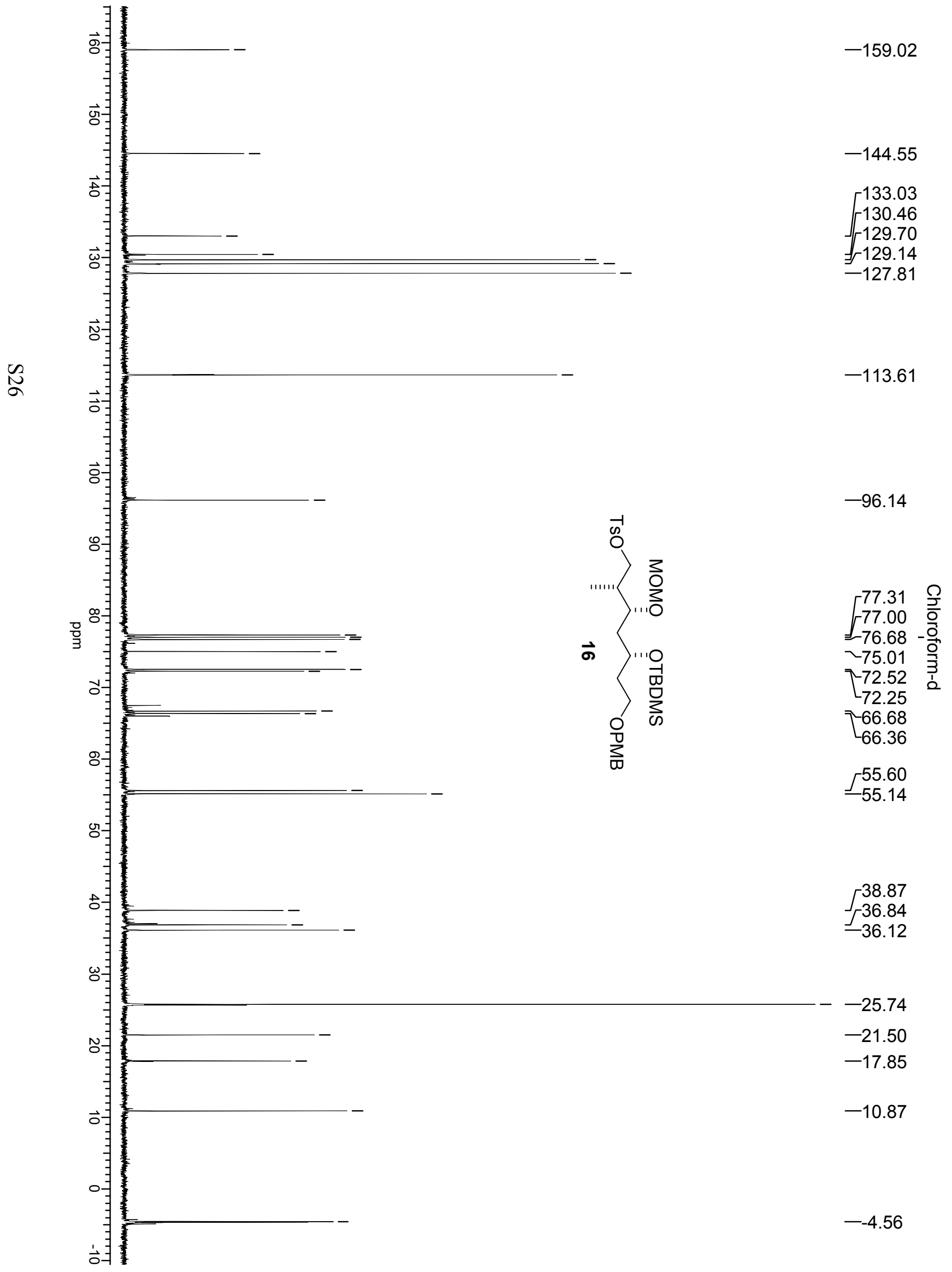




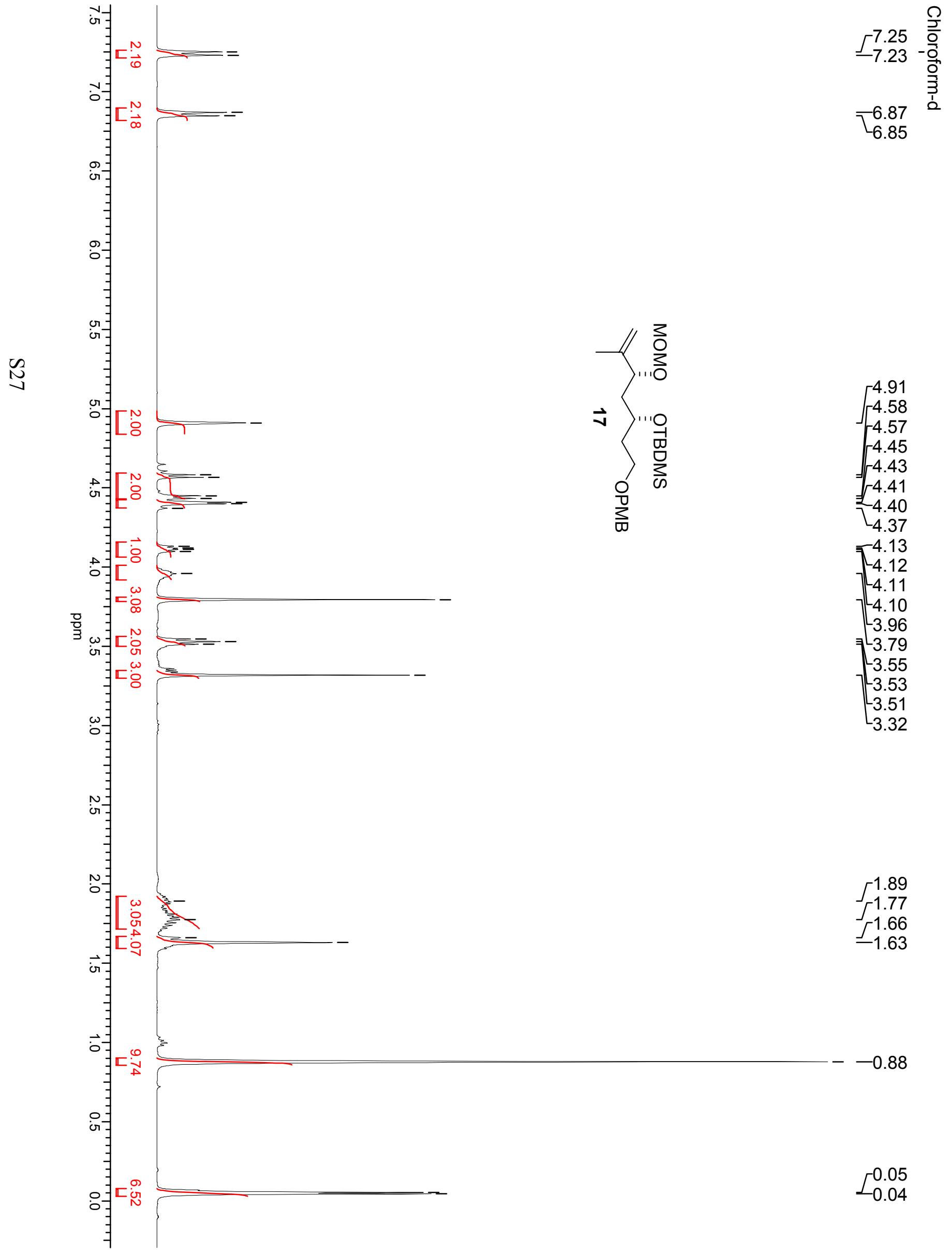




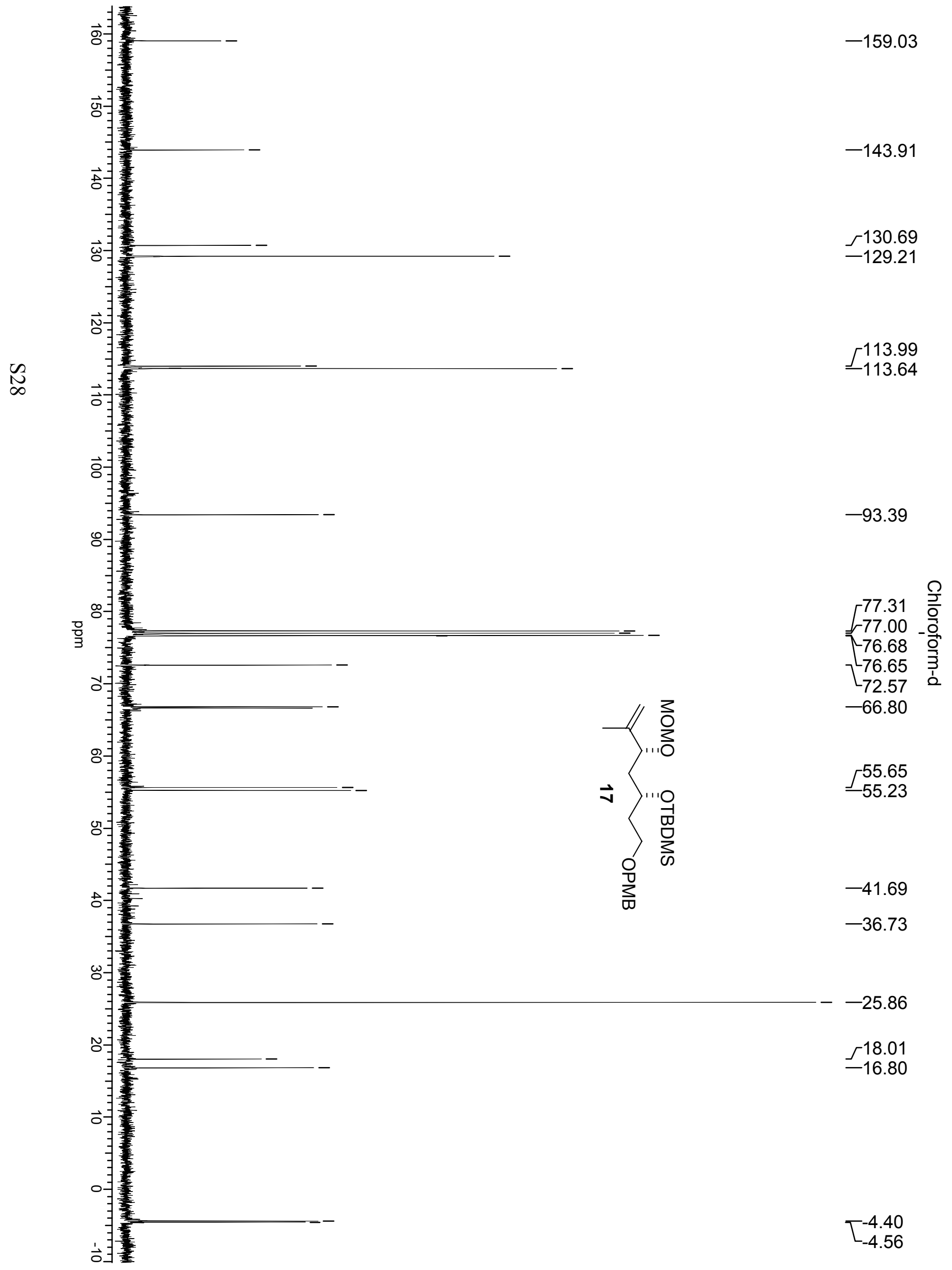




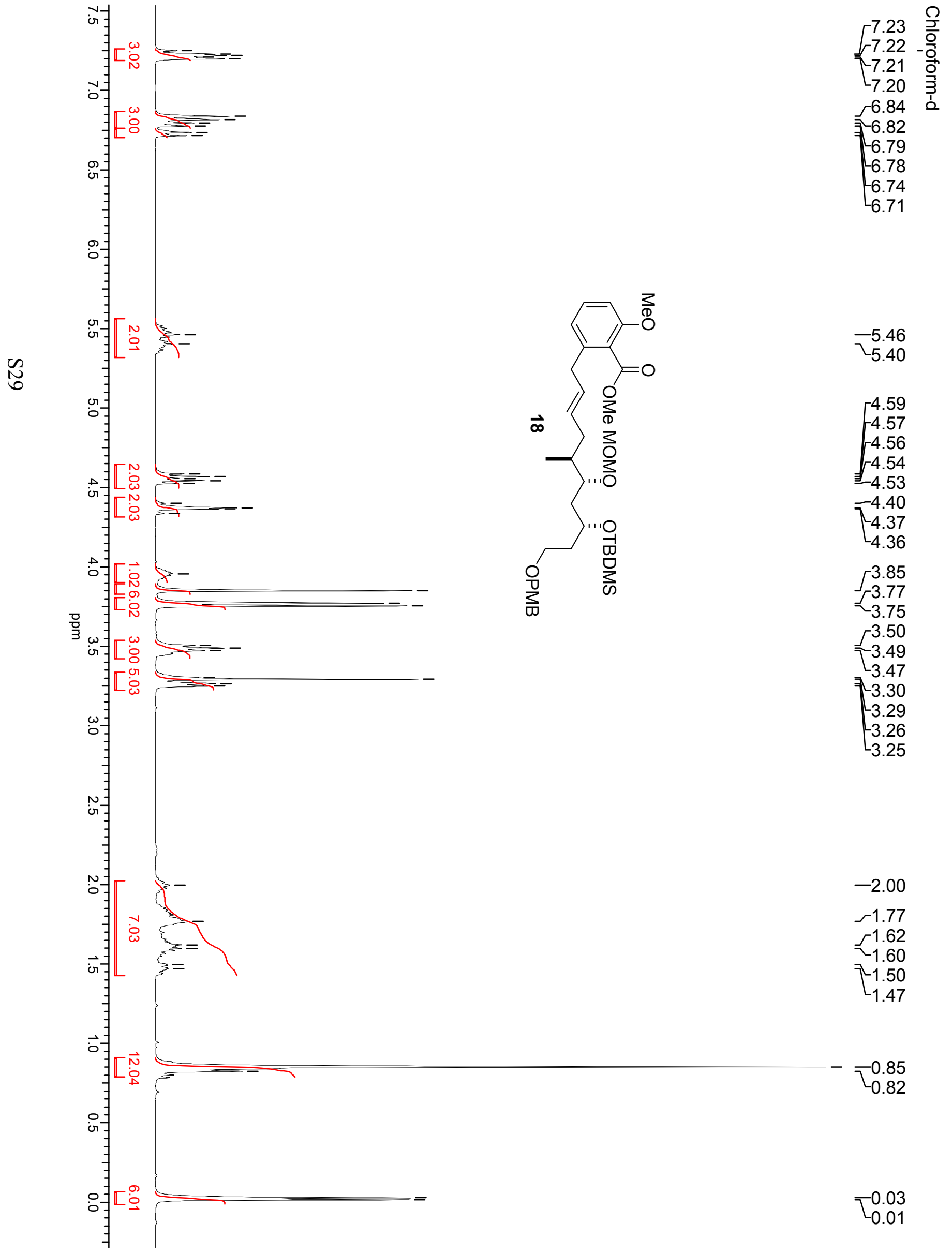




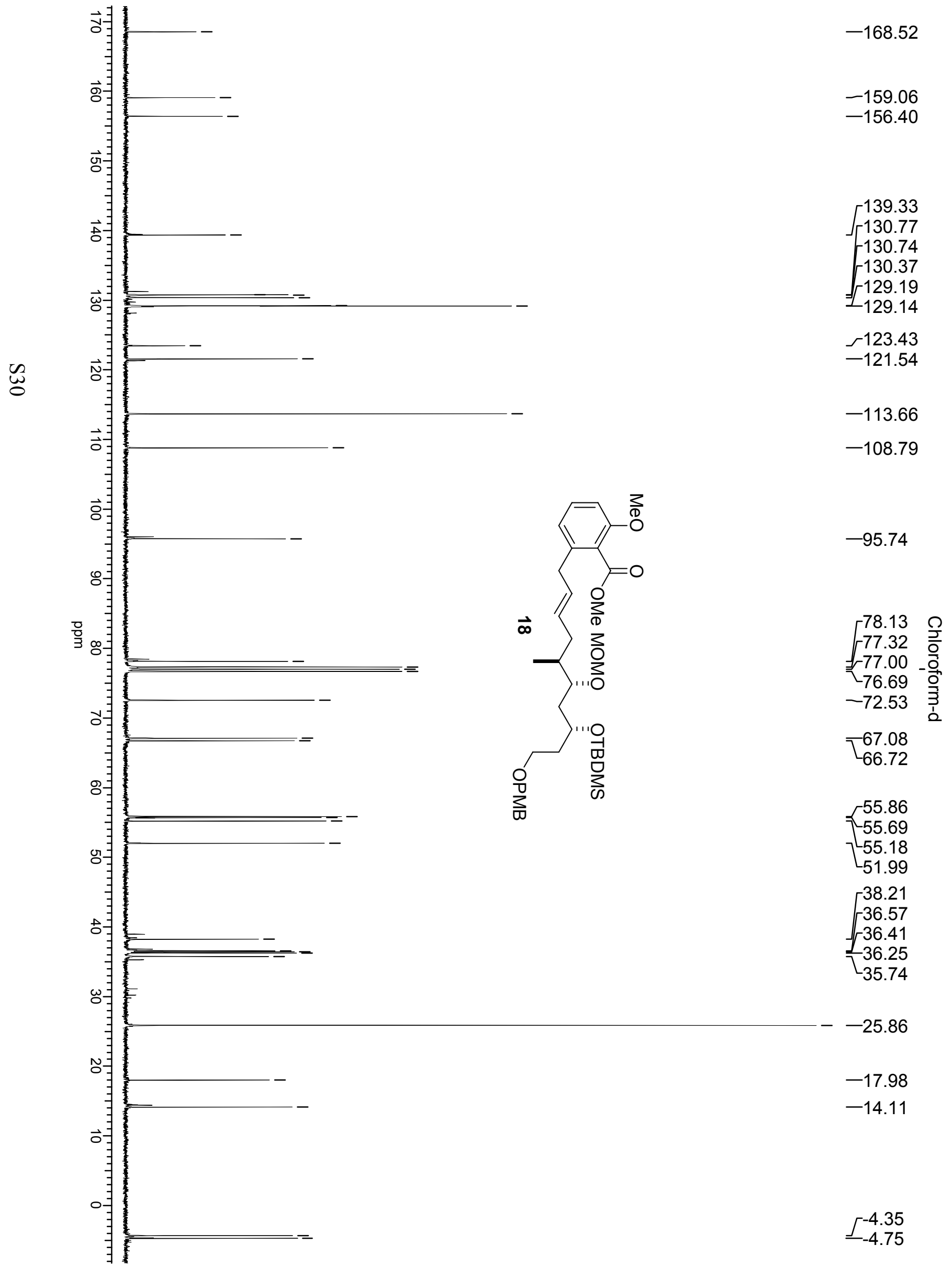




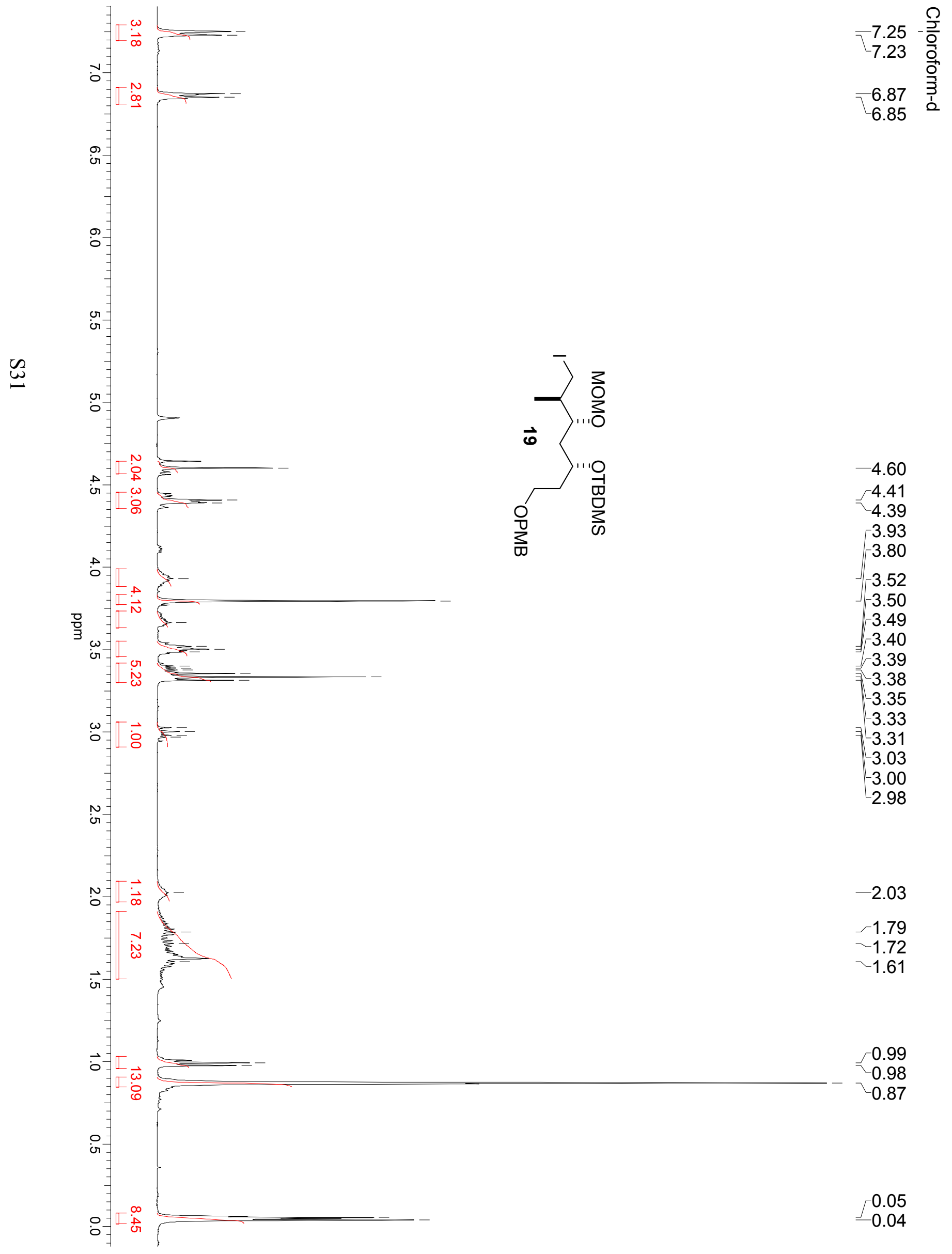




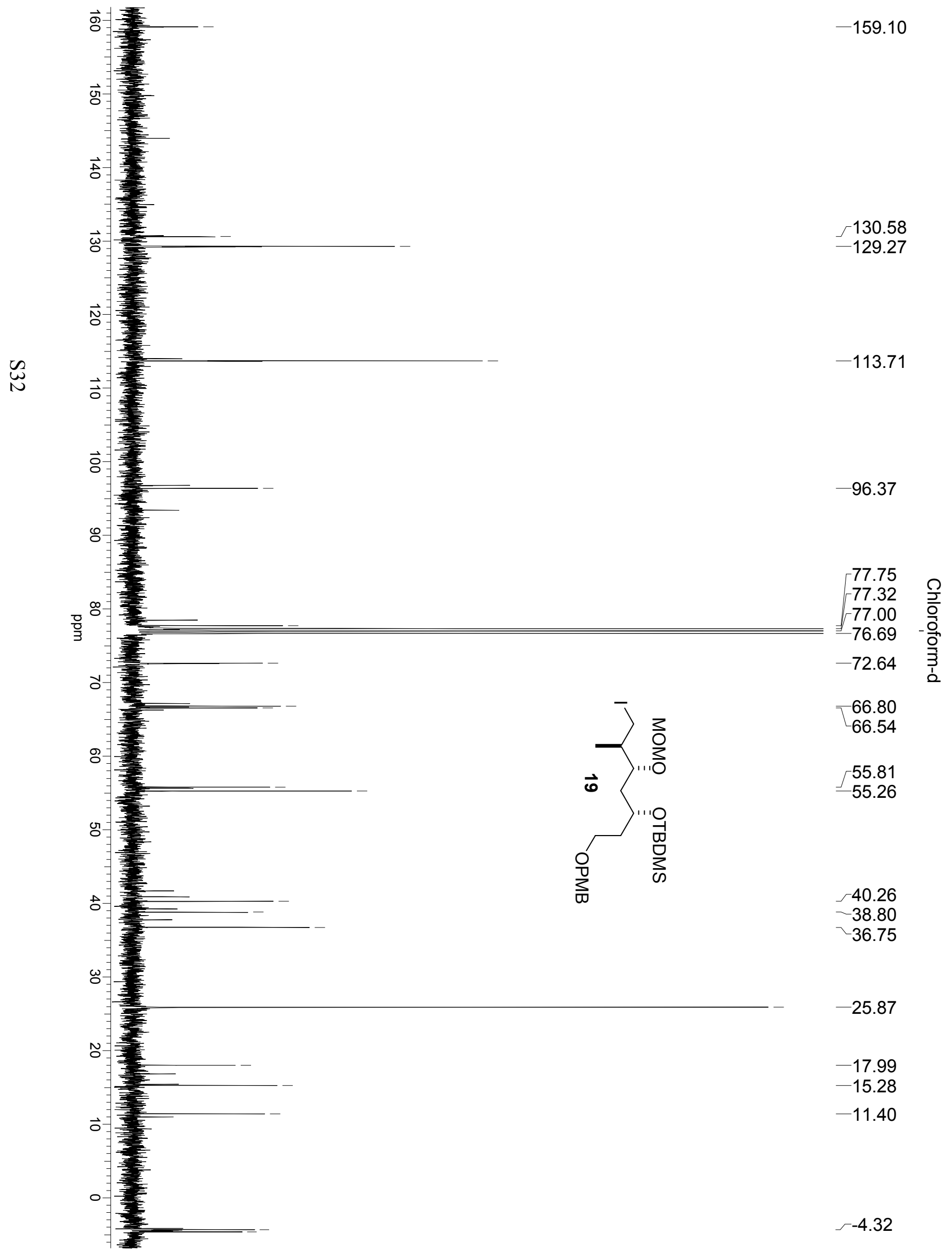




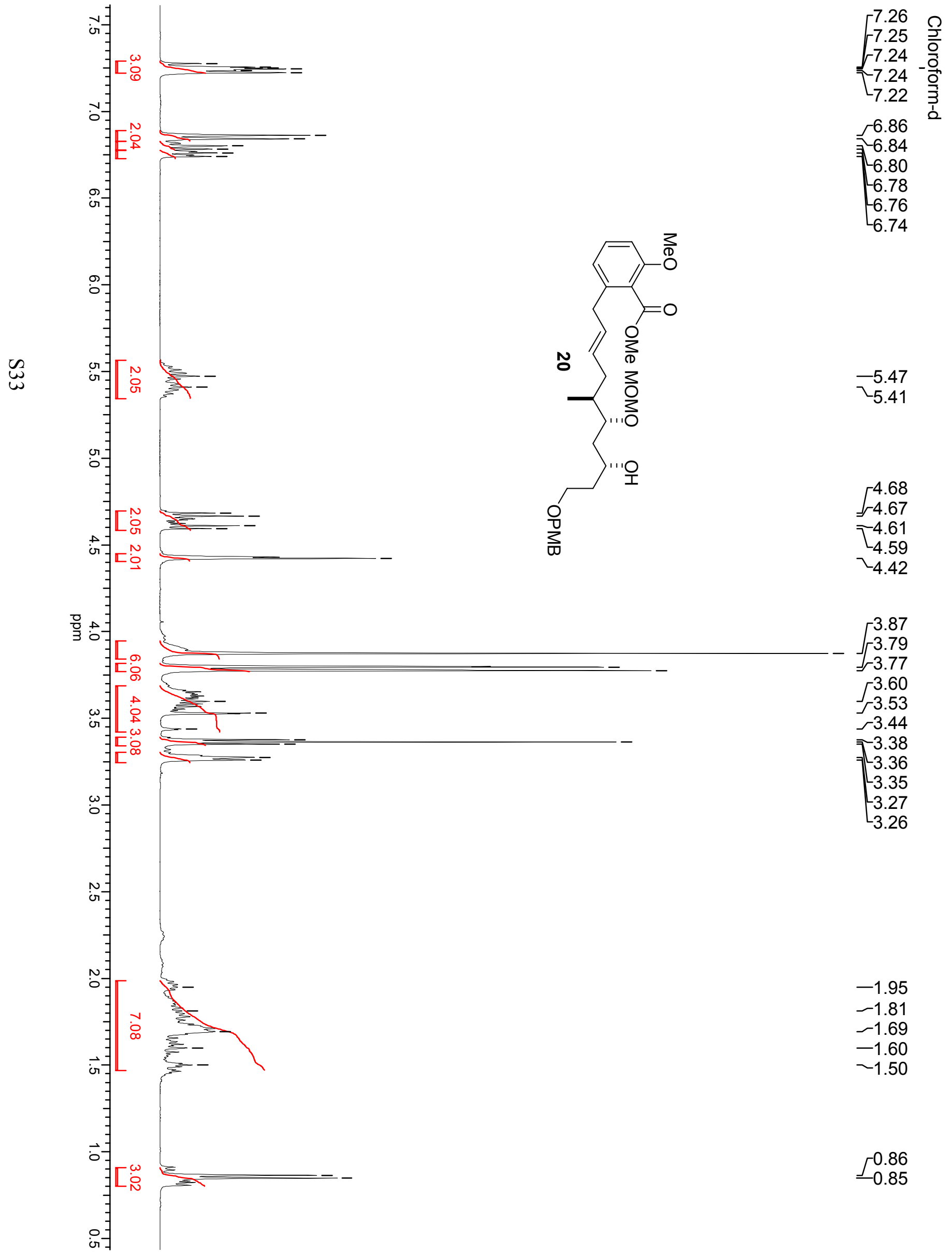




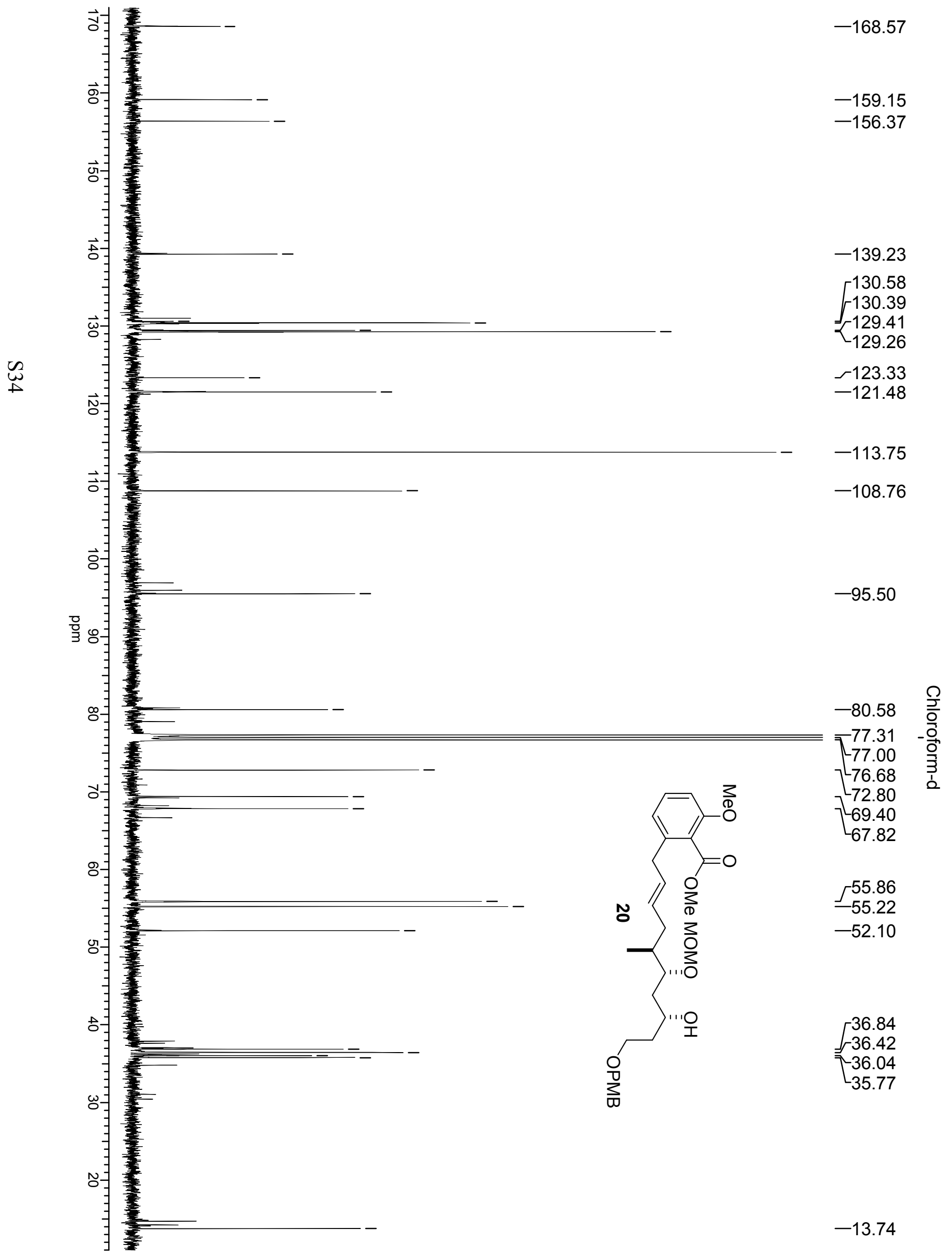




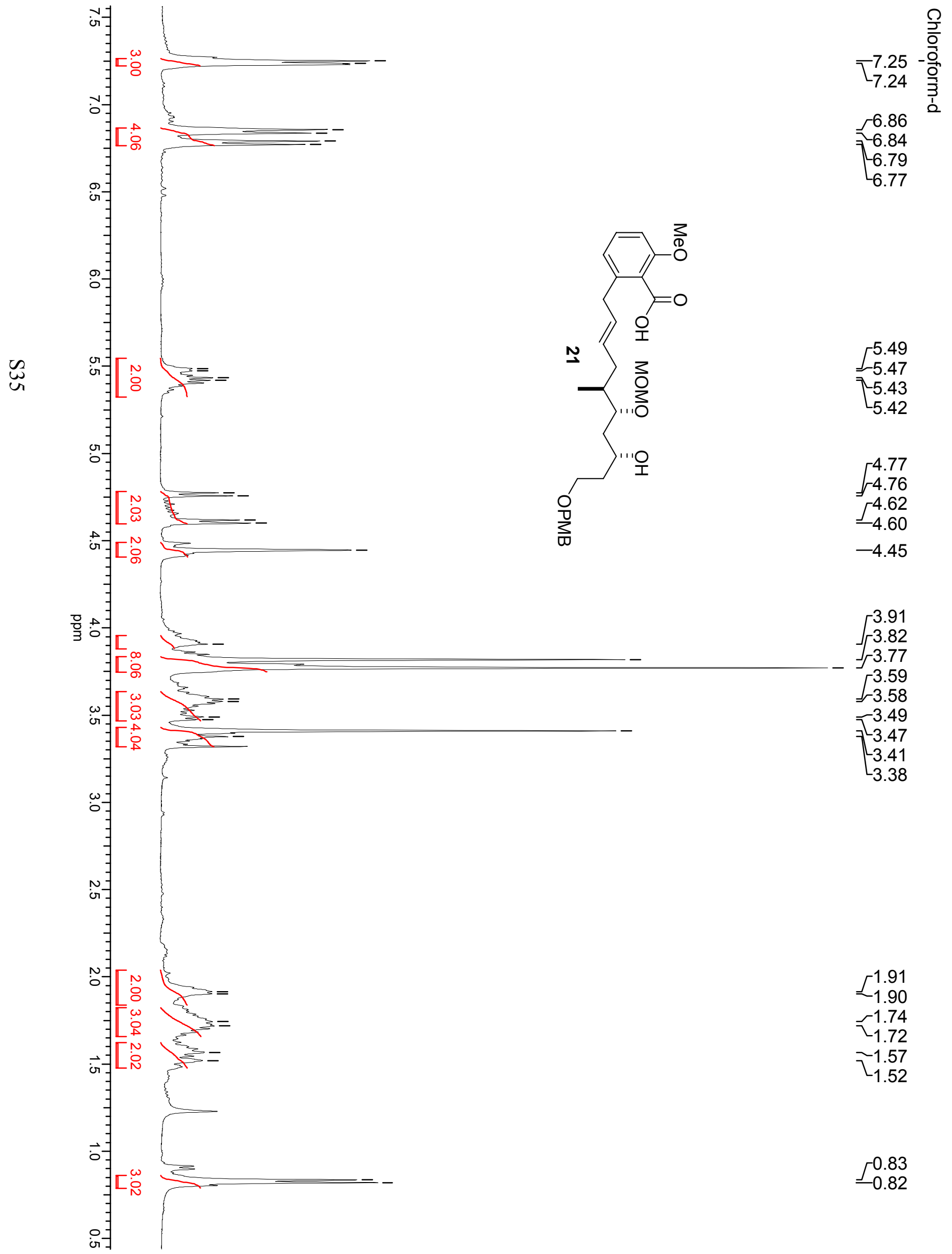




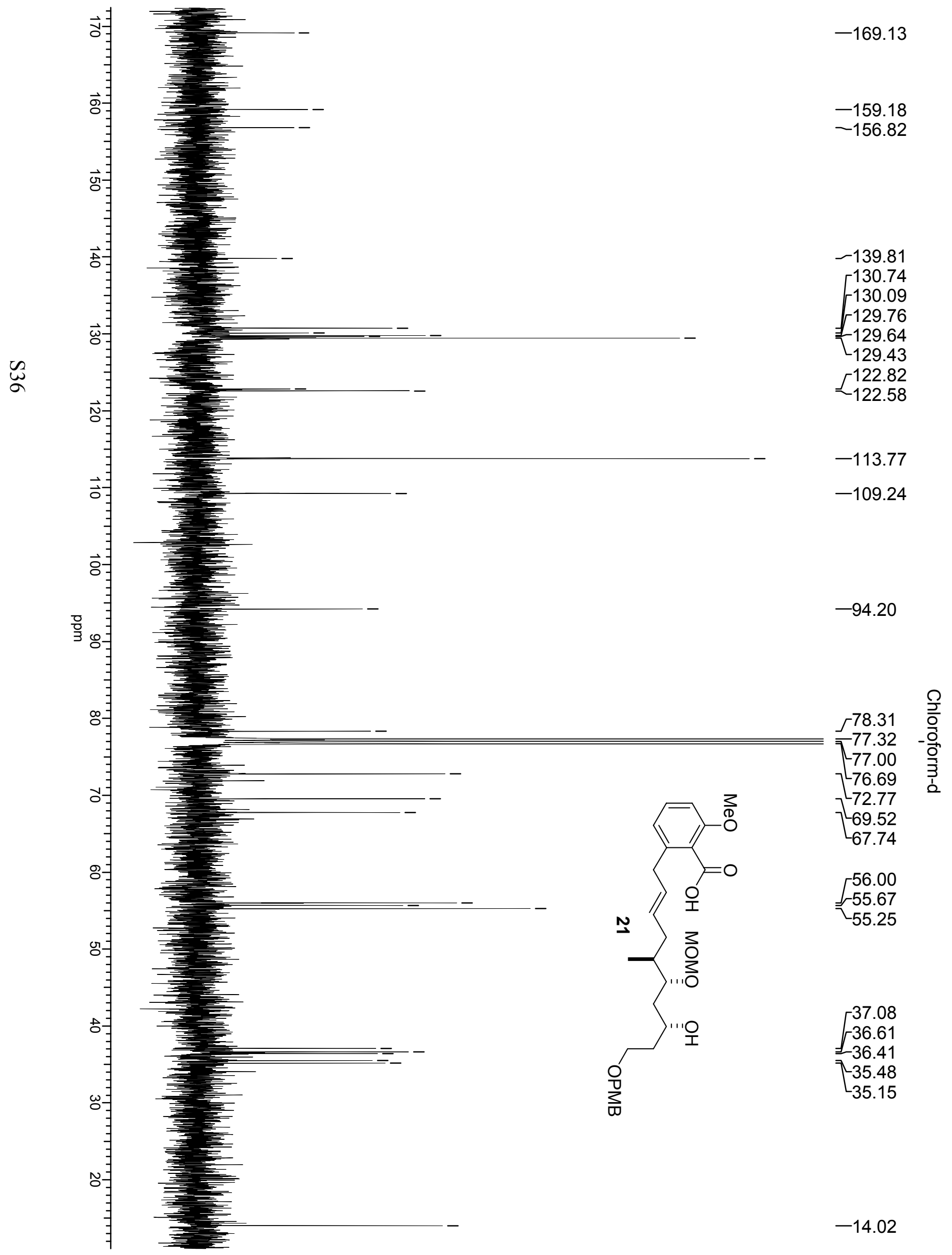




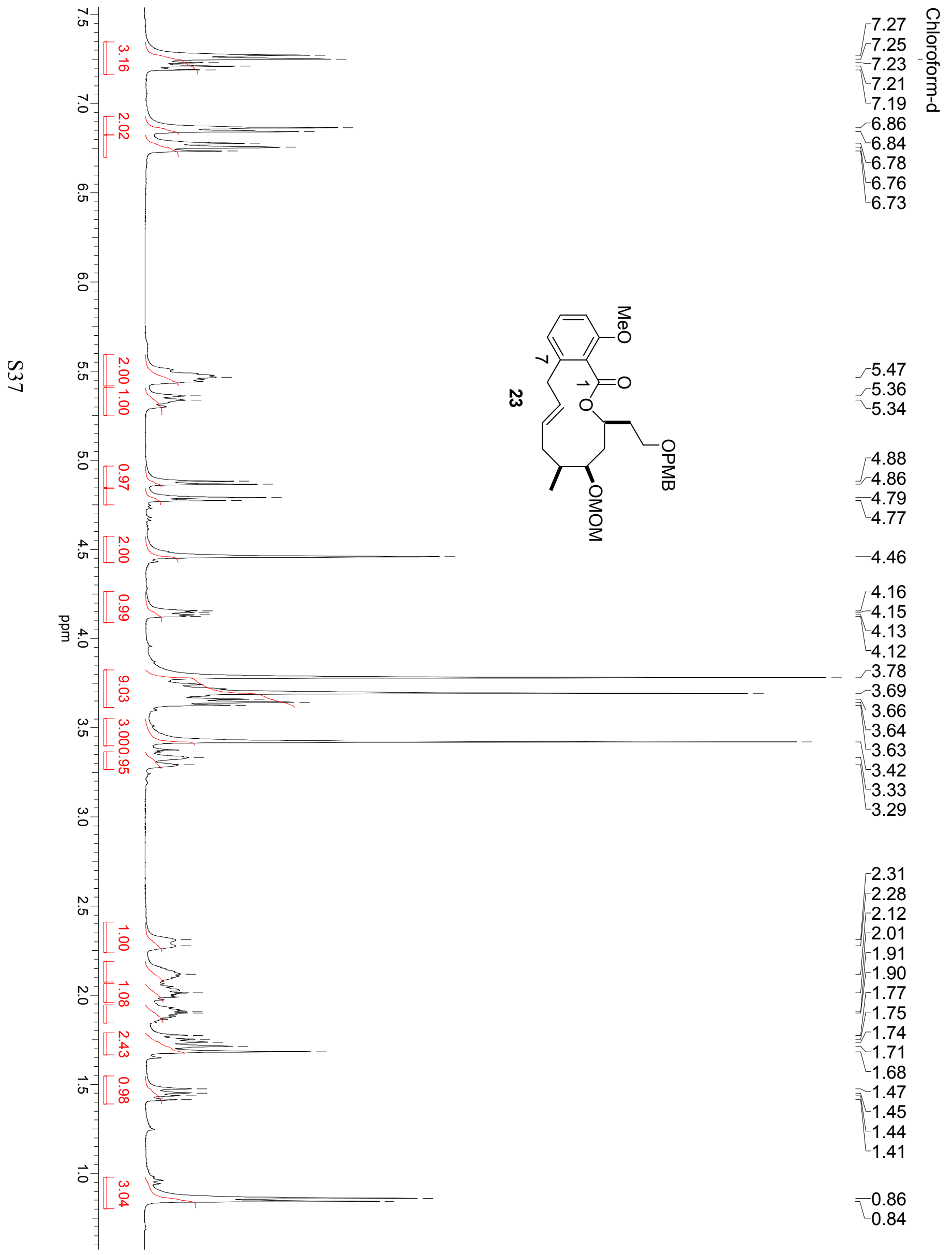




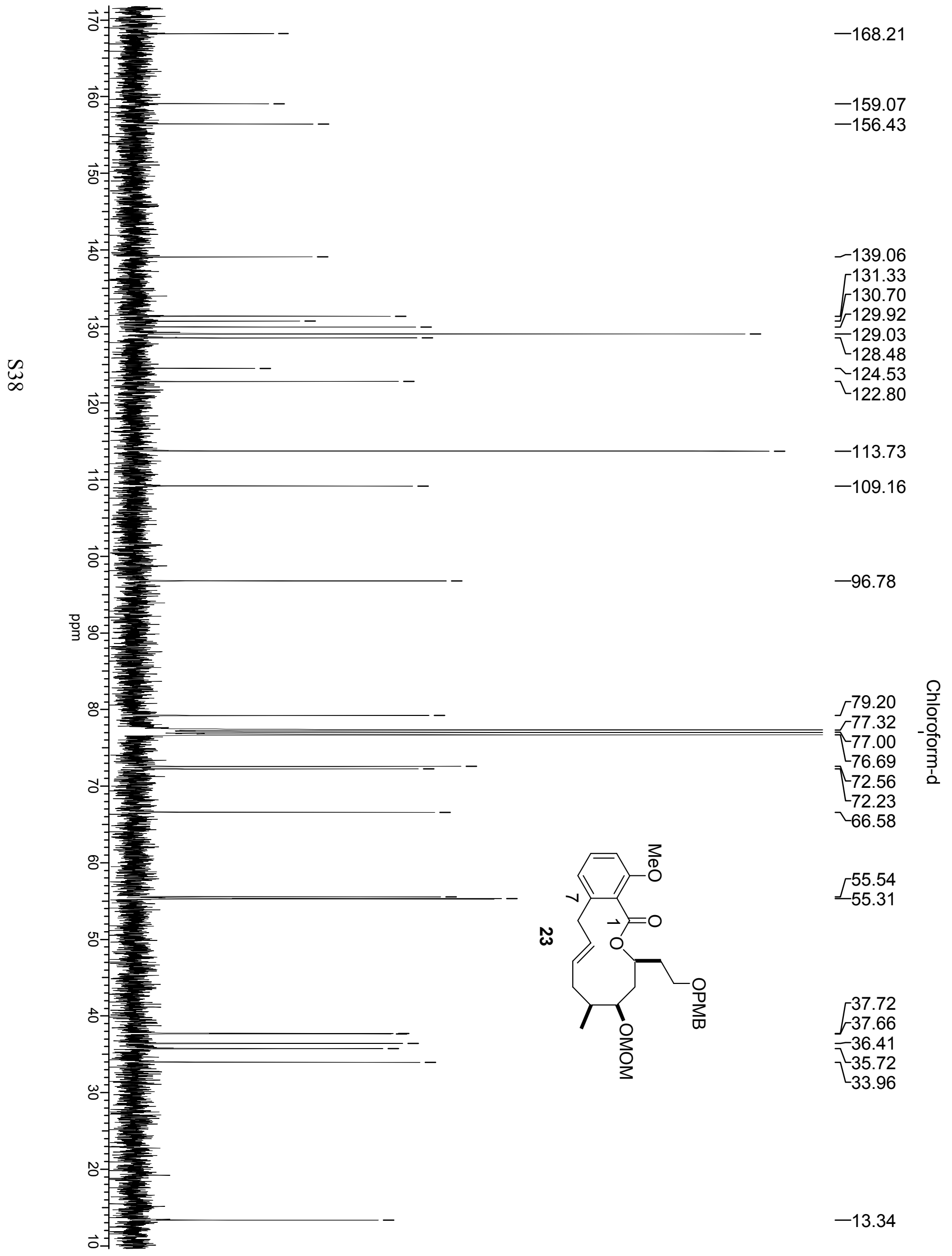

